\title{
Antibacterial Efficacy of \\ Surgical Hand Preparation Products \\ Used by Veterinary Students
}

\author{
BY \\ Po-Yen Chou
}

\begin{abstract}
A Thesis
Submitted to the Graduate Faculty

in Partial Fulfilment of the Requirements for the Degree of

MASTER OF SCIENCE

Department of Companion Animals

Faculty of Veterinary Medicine

Atlantic Veterinary College

University of Prince Edward Island

(C) July 2017, P. Chou
\end{abstract}




\section{THESIS/DISSERTATION NON-EXCLUSIVE LICENSE}

\begin{tabular}{|l|l|}
\hline Family Name: Chou & Given Name, Middle Name (if applicable): Po-Yen \\
\hline Full Name of University: University of Prince Edward Island \\
\hline Faculty, Department, School: Faculty of Veterinary Medicine, Companion Animal \\
\hline $\begin{array}{l}\text { Degree for which thesis/dissertation was presented: Master of } \\
\text { Science }\end{array}$ & Date Degree Awarded: \\
\hline $\begin{array}{l}\text { Thesis/dissertation Title: Antibacterial Efficacy of Several Surgical Hand Preparation Products Used by } \\
\text { Veterinary Students }\end{array}$ \\
\hline \begin{tabular}{l} 
Date of Birth. NA \\
\hline
\end{tabular}
\end{tabular}

In consideration of my University making my thesis/dissertation available to interested persons, I,

Po-Yen Chou

hereby grant a non-exclusive, for the full term of copyright protection, license to my University,

The university of Prince Edward Island:

(a) to archive, preserve, produce, reproduce, publish, communicate, convert into any format, and to make available in print or online by telecommunication to the public for non-commercial purposes;

(b) to sub-license to Library and Archives Canada any of the acts mentioned in paragraph (a).

I undertake to submit my thesis/dissertation, through my University, to Library and Archives Canada. Any abstract submitted with the thesis/dissertation will be considered to form part of the thesis/dissertation.

I represent that my thesis/dissertation is my original work, does not infringe any rights of others, including privacy rights, and that I have the right to make the grant conferred by this non-exclusive license.

If third party copyrighted material was included in my thesis/dissertation for which, under the terms of the Copyright Act, written permission from the copyright owners is required I have obtained such permission from the copyright owners to do the acts mentioned in paragraph (a) above for the full term of copyright protection

I retain copyright ownership and moral rights in my thesis/dissertation, and may deal with the copyright in my thesis/dissertation, in any way consistent with rights granted by me to my University in this non-exclusive license.

I further promise to inform any person to whom I may hereafter assign or license my copyright in my thesis/dissertation of the rights granted by me to my University in this non-exclusive license.

\begin{tabular}{|l|l|}
\hline Signature & Date \\
\hline
\end{tabular}




\section{University of Prince Edward Island \\ Faculty of Veterinary Medicine \\ Charlottetown}

\section{CERTIFICATION OF THESIS WORK}

We, the undersigned, certify that Dr. Po-Yen Chou, candidate for the degree of

Master of Science has presented his thesis with the following title:

\section{Antibacterial Efficacy of Surgical Hand Preparation Products Used by Veterinary Students}

that the thesis is acceptable in form and content, and that a satisfactory knowledge of the field covered by the thesis was demonstrated by the candidate through an oral examination held on August 22, 2017.

\section{Examiners:}

Dr. Aimie Doyle (Co-Supervisor)

Dr. Hans Gelens (Chair)

Dr. James Dundas

Dr. Pierre Amsellem

Dr. Anne Muckle

Date: 


\begin{abstract}
Objective: To compare antibacterial efficacy of various surgical hand preparation protocols used by veterinary students.
\end{abstract}

Study Design: Prospective, randomized, controlled study.

Study Population: Forty-five third-year veterinary students

Methods: The participants were randomly assigned to the following groups for hand preparation product and time combinations: non-abrasive hand scrub method with $4 \%$ chlorhexidine gluconate $(\mathrm{CH})$; hand rub with a mixture of 30\% 1-propanol and $45 \% 2$ propanol solution (MPS); hand rub with 70\% 2-propanol solution (IPS); or hand rub with $61 \%$ ethanol solution and $1 \%$ chlorhexidine gluconate $(\mathrm{ES} / \mathrm{CH})$. Each of these four groups was subdivided into three conditions, based on contact time: $1.5 \mathrm{~min}, 3 \mathrm{~min}$, or $5 \mathrm{~min}$. There were thus 12 conditions overall. Each of the 45 participants was randomly assigned to four groups in turn. Antibacterial efficacy was assessed by comparing bacterial reduction and culture rate of gram-positive, gram-negative, coagulase positive Staphylococcus spp. and spore-forming bacteria after surgical hand preparation and after the students had performed surgery. Log reductions of total bacteria colonyforming units (CFU/ml) were compared using multivariate analysis of variance. The culture rates were compared using multivariate logistic regression.

Results: Immediately after surgical hand preparation, $\mathrm{CH}$ and ES/CH provided significantly greater bacterial count (logCFU) reduction, and lower positive culture rates 
for gram-positive and spore-forming bacteria, compared with MPS and IPS $(P<0.05)$.

Increases in contact time did not provide significant improvement in bacterial reduction.

By the end of surgery, ES/CH provided significantly greater bacterial count reduction compared with IPS, and lower positive culture rates for gram-positive bacteria, compared with the $\mathrm{CH}, \mathrm{MPS}$ and IPS groups $(P<0.05)$. An increase in contact time significantly improved logCFU reduction in the ES/CH and MPS groups $(P<0.001$ and $P=$ 0.023 respectively.)

Conclusions: $\mathrm{ES} / \mathrm{CH}$ hand rubs or $\mathrm{CH}$ scrubs for surgical hand preparation are recommended for veterinary students. 
Acknowledgments

I would like to acknowledge my supervisors, Dr. Aimie Doyle, Dr. J McClure and Dr. Trina Bailey for giving me this opportunity to complete a Masters Project, I appreciate your support and mentorship.

I would also like to thank Dr. Anne Muckle, Dr. Pierre Amsellem and Dr. Stephanie Hamilton for serving on my Masters Supervisory Committee. Thank you for your support and enthusiasm. You provided valuable opinions on my study.

Thank you to Dr. Jeffery Lewis for providing the mass spectrometry, Matthew Saab and Beatrice Despres for teaching me laboratory techniques necessary for my study. Your expertise and guidance helped me complete this project.

Thank you Dr. Henrik Stryhn for your statistical support.

Thank you to Atlantic Veterinary College Internal Research Grant Fund for financial support of the study

Thank you to my resident mates, Drs. Julie Walter, Shiori Arai, Jonathan Lichtenberger, Aisha Young for your support.

To my parents and Yi-Nin, who have always been supportive for me to fulfill my dream. I love you! 
Table of contents

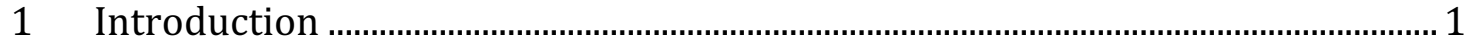

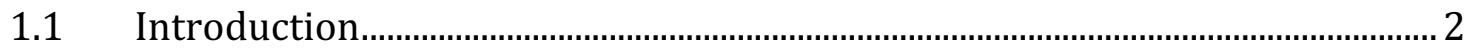

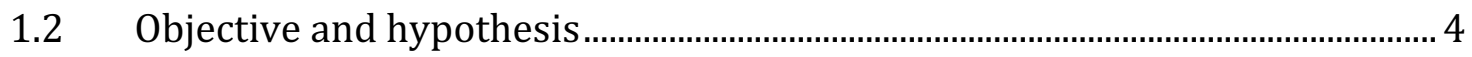

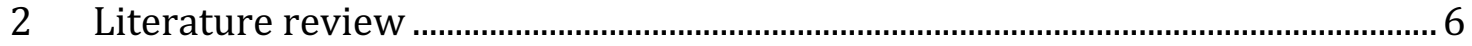

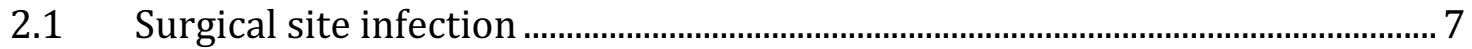

2.1.1 Incidence of surgical site infection in veterinary medicine ............................. 10

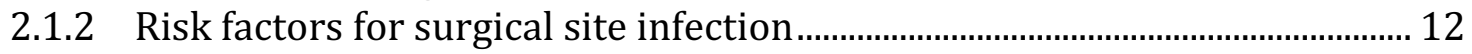

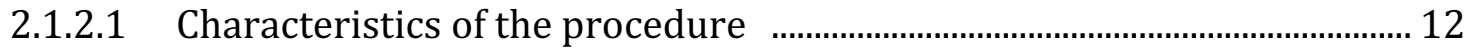

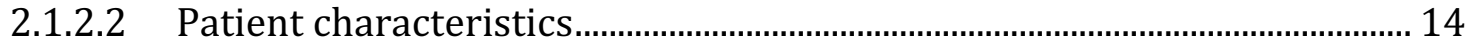

2.1.2.3 Environmental factors....................................................................................... 15

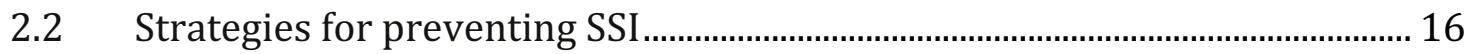

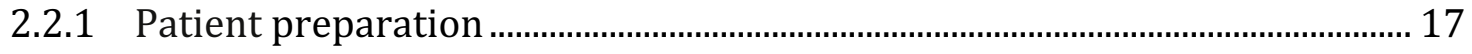

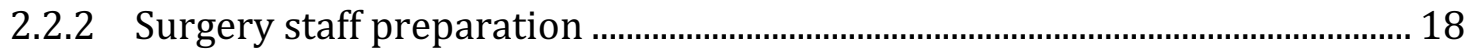

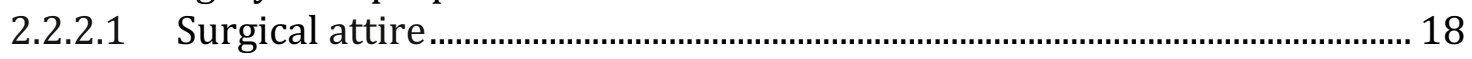

2.2.2.2 Hand preparation for surgery...................................................................... 20

$2.3 \quad$ Products for hand preparation before surgery .............................................. 21

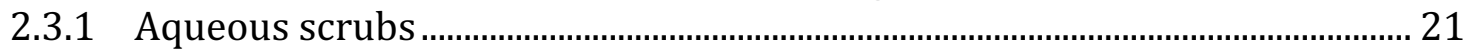

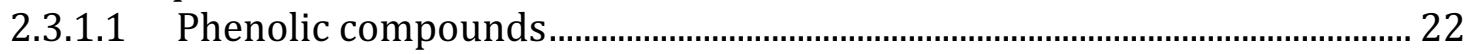

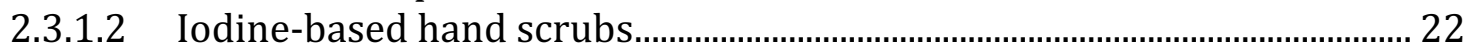

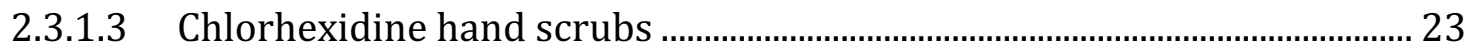

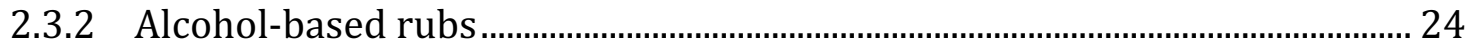

2.3.3 Selection of surgical hand preparation products ............................................ 24

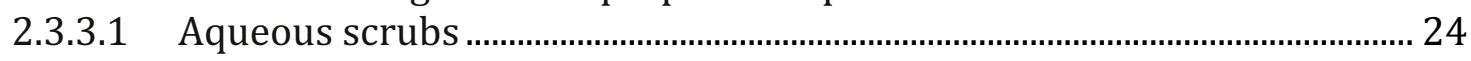

2.3.3.2 Hand rubs containing alcohol and other active ingredients....................... 25

2.4 Comparison of pre-surgical hand preparation methods .................................. 26

2.4.1 Steps before starting surgical hand preparation ............................................... 26

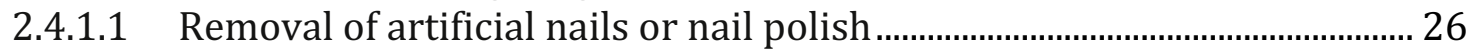

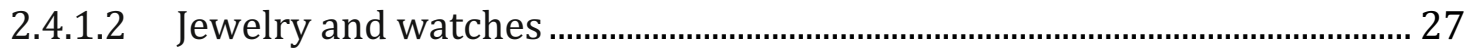

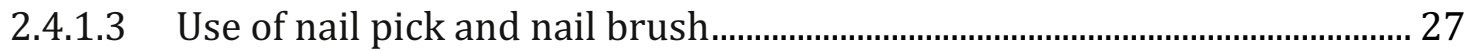

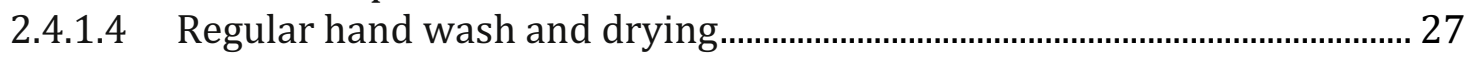

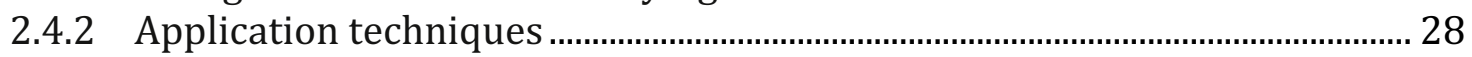

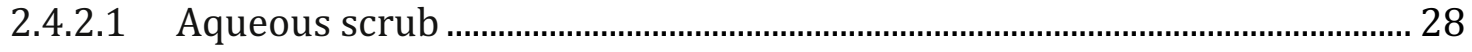

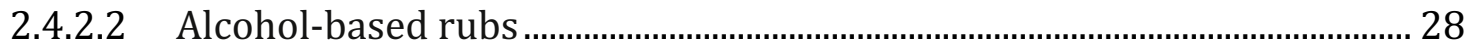

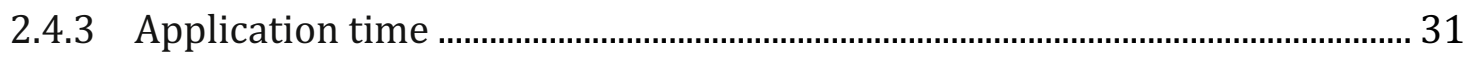

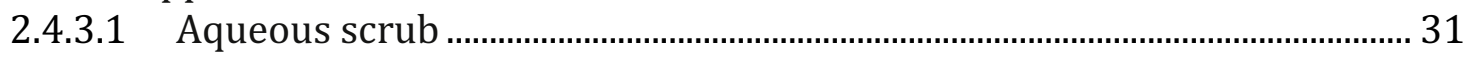

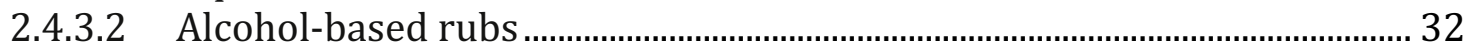

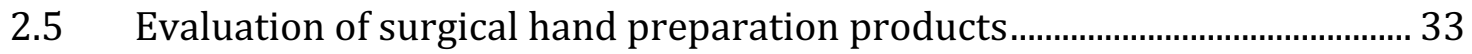

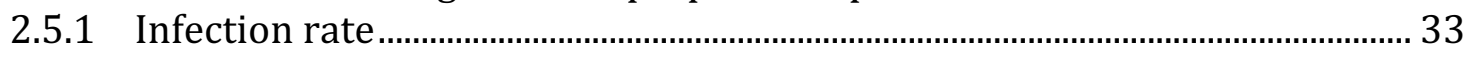

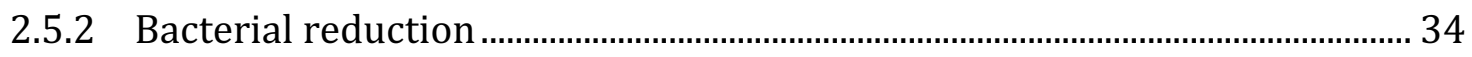

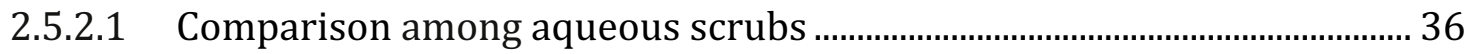

2.5.2.2 Comparison between aqueous scrub and alcohol-based rubs ................... 37

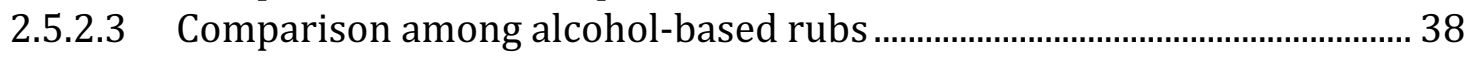

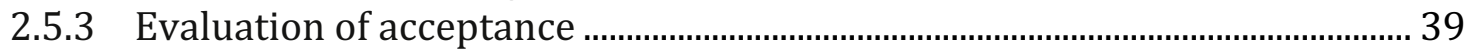


2.5.4 Cost and safety.................................................................................................. 40

2.6 Surgical hand preparations: unanswered questions ....................................... 41

2.6.1 Efficacy of aqueous scrub and ABR among veterinary students ................... 42

2.6.2 Optimal application time for ABR among veterinary students ...................... 42

2.6.3 Selective efficacy of the alcohol based rubs..................................................... 43

3 Materials and methods ........................................................................................ 44

3.1 Materials and methods ………………………….............................................. 45

3.1.1 Surgical hand preparation protocols .................................................................. 45

3.1.2 Sample collection ........................................................................................... 47

3.1.3 Aerobic culture, bacterial count and bacterial isolation .................................. 48

3.2 Statistical analysis........................................................................................ 49

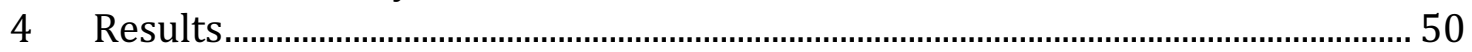

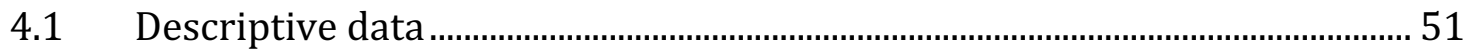

4.2 Aerobic bacterial reduction .......................................................................... 51

4.3 Aerobic bacteria isolation............................................................................. 55

4.3.1 Gram-positive aerobic bacteria..................................................................... 55

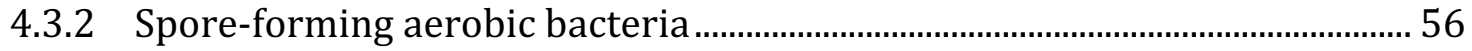

5 Discussion ............................................................................................................. 59

5.1 Antibacterial efficacy of the tested products ..................................................... 60

5.2 The effects of increased contact time on bacterial reduction .........................6 61

5.3 Selective bacterial inhibition of pure alcohol based rubs................................. 62

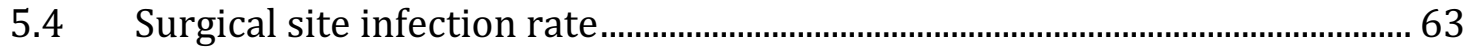

5.5 Limitations ......................................................................................................... 64

5.6 New FDA standard for testing surgical hand antisepsis .................................. 65

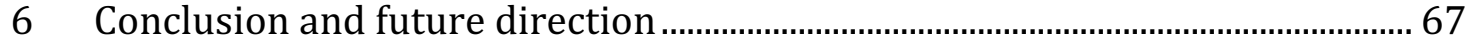

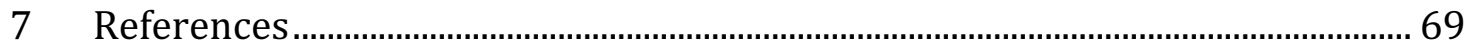




\section{List of figures}

Figure 1 Surgical hand preparation technique with an alcohol-based hand rub formulation.

Figure 2 Mean logCFU reduction immediately after surgical hand preparation (POST) using various products.

Figure 3 Mean logCFU reduction measured at the end of surgery (END) after using

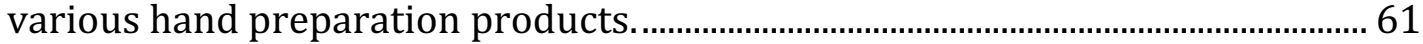


List of tables

Table 1 Center for Disease Control definition of surgical site infection .......................... 8

Table 2. Incidence of surgical site infection in veterinary medicine .............................. 10

Table 3 Positive culture rate for gram-positive, gram-negative, spore-forming bacteria and coagulase-positive Staphylococcus spp. using different surgical

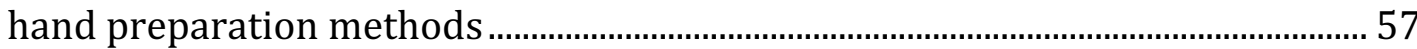


List of abbreviations (in the order of appearance)

SSI - Surgical site infection

CH - 4\% chlorhexidine gluconate

ABR - Alcohol-based hand rub

WHO - World Health Organization

PI - Povidone iodine

MPS - mixture of 30\% 1-propanol and 45\% 2-propanol solution

IPS - 70\% 2-propanol solution

ES/CH - $61 \%$ ethanol solution with 1\% chlorhexidine gluconate

CFUs - Colony-forming units

TPLO - Tibial plateau leveling osteotomy

MRSA - Methicillin-resistant Staphylococcus aureus

FDA - U.S. Food and Drug Administration

PRE - Before surgery hand preparation

POST - After surgery hand preparation

END - By the end of surgery

OHE - Ovariohysterectomy 
1 INTRODUCTION 


\subsection{Introduction}

Surgical site infection (SSI) is a major post-operative complication in both human and veterinary medicine. Such infections lead to delayed wound healing, prolonged hospital stays, increased use of antibiotics, increased medical costs and a potentially fatal outcome..$^{1,2}$ Unintentional transfer of microorganisms to patients during surgery is a cause of SSI. Although wearing sterile gloves helps to prevent the transfer of microorganisms from the hands of surgical team members to the patient, gloves often become perforated. A recent study showed that at least one glove became defective in $26.2 \%$ of surgical procedures at a small animal referral hospital, and only $30.8 \%$ of the glove punctures were noted by the wearer. ${ }^{3}$ The rate of glove perforation is even higher during large animal surgeries, with at least one glove becoming defective in $66 \%$ of surgical procedures. ${ }^{4}$ Therefore, proper surgical hand preparation is regarded as an important step for prevention of SSIs.1,2,5

Surgical hand preparation methods have evolved gradually since Joseph Lister first demonstrated the efficacy of carbolic acid for skin disinfection in 1867.6 Currently, aqueous scrub with $4 \%$ chlorhexidine $(\mathrm{CH})$ detergent and alcohol-based hand rub (ABR) are both recommended by the World Health Organization (WHO) for surgical hand preparation. ${ }^{7}$ In recent decades, the recommended scrub time for $\mathrm{CH}$ has decreased from $10 \mathrm{~min}$ to $5 \mathrm{~min}$. The use of brushes is no longer recommended because of reported skin irritations and micro-abrasions, increased bacterial colonization ${ }^{8,9}$, poor compliances ${ }^{10}$, and excessive water and solid waste. ${ }^{11}$

Alcohol-based hand rub products contain short-chain alcohols as the primary 
active ingredient, most commonly isopropanol and ethanol. Long-acting compounds such as $\mathrm{CH}$ or quaternary ammonium compounds may also be included in the formula. The use of ABRs has resulted in reduced preparation time, cost and water usage, ${ }^{11}$ and ABR products are reportedly at least as effective as CH. ${ }^{12}$ Although frequently marketed as a waterless hand scrub, an initial hand wash is with soap and water is recommended by the WHO to help remove any soil, blood and bacteria spores prior to applying ABR.7,13

The recommended contact time for surgical hand preparation using a mixture of 30\% 1-propanol and 45\% 2-propanol solution (MPS) (Sterilium®, BODE Chemie GmbH \& Co. KG, Hamburg, Germany) is 1.5 min. For 70\% 2-propanol solution (IPS) (Manorapid ${ }^{\circledR}$, Antiseptica Chem.Pharm. Produkte GmbH, Pulheim, Germany), the recommended contact time is $3 \mathrm{~min} .{ }^{9} \mathrm{~A}$ contact time of $1.5 \mathrm{~min}$ is recommended for a product containing $61 \%$ ethanol solution with $1 \%$ chlorhexidine gluconate $(\mathrm{ES} / \mathrm{CH})$ (Avagard $®$, 3M, Saint Paul, MN). Because of the varying recommended application methods and contact times ${ }^{7,14}$, the use of ABR might be more prone to error than $\mathrm{CH}$ scrub. ${ }^{9}$ To help prevent confusion, WHO proposes a standard application method and suggests that users follow the contact times recommended by manufacturers. ${ }^{7}$

Alcohol-based hand rubs are rarely used by veterinary surgeons; $79.9 \%$ of veterinary surgeons still use only disinfectant soap or scrub for their surgical hand preparation. ${ }^{15}$ With the increasing acceptance of surgical hand rubs, it is crucial for veterinarians to be familiar with the techniques and for a good standard of practice to be established in veterinary medicine. However, the author observed that most 
veterinary schools in North America do not provide training in proper ABR application during the curriculum. Before surgical hand rubs are brought into educational settings, the efficacy of ABRs and the effect of extended contact time require further evaluation.

\subsection{Objective and hypothesis}

The purpose of this study was to evaluate the antimicrobial effect of four hand preparation products - CH, MPS, IPS and ES/CH - at the recommended and extended contact times, among a group of third-year veterinary students. The study had several objectives:

- To compare the reduction of bacterial colony-forming units per milliliter (CFU/ml) on the hands of third-year veterinary students, after they had prepared their hands for surgery using various products.

- To compare the effect of an increase or decrease in contact time - between the hands and the hand preparation products tested - on the antibacterial efficacy of those products.

- To identify bacteria cultured from hands before and after surgical hand preparation, and to compare the results for different surgical hand scrubs.

We hypothesized that at manufacturer-recommended application times, commercial surgical hand rubs would reduce the bacteria count and the culture rate of gram-positive, gram-negative, spore forming bacteria and coagulase positive staphylococcus as effectively as the non-abrasive $\mathrm{CH}$ hand scrub technique, among veterinary students. We further hypothesized that an increased contact time with 
surgical hand preparations would provide additional reduction in bacterial counts and culture rate. 
2 LITERATURE REVIEW 


\subsection{Surgical site infection}

Surgical site infection is one of the most common post-operative complications. In human medicine, approximately 2 million nosocomial infections occur annually in the United States and 15\% of these are SSIs. ${ }^{16-19}$ Depending on the surgical procedure, SSI occurs in $0.8 \%$ to $40 \%$ of small animal surgery cases ${ }^{20-25}$ and in $8.3 \%$ to $52 \%$ of equine surgery cases. ${ }^{26-27,28}$

The US Center for Disease Control and Prevention has developed standardized surveillance criteria for SSIs. The infections are categorized as being either superficial, deep, or organ / space infections. ${ }^{21,29}$ According to the definitions, the diagnosis of SSI is based on clinical symptoms and does not require a positive culture of infectious organism. (Table 1).

In general, morbidity from SSI correlates well with the severity of infection; however, clinically even minor SSIs can cause severe morbidity. ${ }^{30}$ The most severe complication due to SSI is mortality; approximately $38 \%$ of deaths among human surgery patients are attributed to SSI.19,30,31 A comprehensive case-control study of 225 matched pairs of human patients, with and without SSI, showed that infected patients were twice as likely to die during the initial postoperative hospitalization compared with uninfected patients. ${ }^{1}$

Surgical site infections also cause increased hospital stays and related health care costs. ${ }^{15,31,32}$ A recent human study reviewed 16 cost analyses and showed that health-care costs for patients with SSIs were twice as high, and hospital stays were 9.7 days longer, compared with patients without SSI. ${ }^{33}$ Additional diagnostic tests, 
therapeutic antibiotic treatments, and surgery all increase the medical costs by an average of $\$ 20,842$ per admission. Annually, additional hospital costs due to SSI in the US exceed $\$ 900$ million, and hospital readmission due to SSI accounts for an additional $\$ 700$ million in health-care spending. ${ }^{34}$

In veterinary medicine, the economic and patient impacts of SSI have been less studied. The tibia plateau leveling osteotomy (TPLO) procedure is a common procedure performed to treat canine cranial cruciate ligament rupture. Surgical site infection after TPLO resulted in a significant increase in postoperative costs and an average of 4.1 additional rechecks, compared with TPLO without SSI. ${ }^{2}$ In horses that underwent long bone fracture repair, cases without SSI were 7.25 times more likely to be discharged from hospital; that is, horses with SSI were 7.25 times more likely to be euthanized while hospitalized. ${ }^{27}$

Table 1 Center for Disease Control definitions of surgical site infection

\begin{tabular}{|l|l|}
\hline Superficial Incisional & $\begin{array}{l}\text { Within } 30 \text { days after surgery. } \\
\text { Only skin or subcutaneous tissue infection. } \\
\text { AND at least one of the following: } \\
\text { 1. Purulent drainage from the incision. } \\
\text { 2. Organisms isolated from tissue or fluid culture. } \\
\text { 3. At least one of the following: pain or tenderness, localized } \\
\text { swelling, redness, or heat; and superficial incision is deliberately } \\
\text { opened by surgeon, unless incision is culture-negative. } \\
\text { 4. Diagnosis of superficial incisional SSI by the surgeon or }\end{array}$ \\
\hline
\end{tabular}




\begin{tabular}{|c|c|}
\hline & attending physician. \\
\hline Deep Incisional SSI 29,35 & $\begin{array}{l}\text { Within } 30 \text { days, or } 1 \text { year with implant. } \\
\text { Involves deep soft tissues (eg, fascial and muscle layers) at the } \\
\text { incision point. } \\
\text { AND at least one of the following: } \\
\text { 1. Purulent drainage from the deep incision. } \\
\text { 2. A deep incision spontaneously dehisces or is deliberately } \\
\text { opened by a surgeon because of fever, localized pain, or } \\
\text { tenderness, unless site is culture-negative. } \\
\text { 3. An abscess or other evidence of infection involving the deep } \\
\text { incision. } \\
\text { 4. Diagnosis of a deep incisional SSI by a surgeon or attending } \\
\text { physician. }\end{array}$ \\
\hline Organ / Space SSI 29,35 & $\begin{array}{l}\text { Within } 30 \text { days, or } 1 \text { year with implant. } \\
\text { Involves any part of the anatomy (eg, organs or spaces) that was } \\
\text { opened or manipulated during an operation. } \\
\text { AND at least one of the following: } \\
\text { 1. Purulent drainage. } \\
\text { 2. Organisms isolated. } \\
\text { 3. An abscess or other evidence of infection on direct examination, } \\
\text { reoperation, or by histopathologic or radiologic examination. } \\
\text { 4. Diagnosis of an organ / space SSI by a surgeon or attending } \\
\text { physician. }\end{array}$ \\
\hline
\end{tabular}




\subsubsection{Incidence of surgical site infection in veterinary medicine}

Several veterinary retrospective studies have reported SSI rates, both the overall infection rate and procedure-specific infections. The overall infection rate for all surgical procedures was between $3 \%$ and $6 \%{ }^{36,37}$ Orthopedic procedures in small animal patients, including TPLO, have a reported SSI rate of between $1.3 \%$ and $21.3 \% .^{38,39}$ In horses, orthopedic procedures - specifically long bone fracture repair - has a reported SSI rate of $28 \%{ }^{27}$ Owing to the retrospective nature of these studies and the lack of active prospective surveillance, the actual infection rates might be higher (Table 2).

Table 2. Incidence of surgical site infections in veterinary medicine

\begin{tabular}{|l|l|l|l|}
\hline \multirow{4}{*}{ Species } & Surgical procedure(s) & SSI incidence & Reference \\
\hline \multirow{5}{*}{ Dog, Cat } & Various & $\mathbf{( \% )}$ & \\
\cline { 2 - 4 } & Clean procedures & $0.8-5.9$ & $37,40,41$ \\
\cline { 2 - 4 } & Clean-contaminated procedures & $2.5-4.5$ & 36,37 \\
\cline { 2 - 5 } & Contaminated procedures & 4.5 & 37 \\
\cline { 2 - 5 } & Dirty procedures & 5.8 & 37 \\
\hline Dog & Total hip replacement & $18.1-40$ & 37 \\
\cline { 2 - 5 } & & $3.1-10$ & 42,43 \\
\hline
\end{tabular}




\begin{tabular}{|c|c|c|c|}
\hline & TPLO & $2.9-21.3$ & $25,38,39,45-48$ \\
\hline & Laparoscopy and video-assisted surgery & 1.7 & 22 \\
\hline & $\begin{array}{l}\text { Extracapsular stifle stabilization and } \\
\text { TPLO }\end{array}$ & 6.1 & 49 \\
\hline & Tibial tuberosity advancement & 2.6 & 50 \\
\hline & Clean orthopedics & 8.3 & 26 \\
\hline & Clean-contaminated orthopedics & 52 & 26 \\
\hline & Long bone fracture repair & 28 & 27 \\
\hline & Carpal arthroscopy & 0.05 & 51 \\
\hline & Laparotomy & 25.4 & 40 \\
\hline
\end{tabular}




\subsubsection{Risk factors for surgical site infection}

The risk factors for SSI have been extensively investigated in both human and veterinary medicine. Several risk factors are correlated with SSI; these can be categorized into procedural, patient and environmental factors.

\subsubsection{Characteristics of the procedure}

The nature of a surgical procedure can have a profound impact on the patient's risk for SSI. The National Academy of Sciences and the National Research Council have developed a wound classification system based on the level of contamination of the wound, as follows:

(1) Clean procedure: non-traumatic, non-inflamed operative wounds in which the respiratory, gastrointestinal, genitourinary and oropharyngeal tracts are not entered.

(2) Clean-contaminated procedure: operative wounds in which the respiratory, gastrointestinal, or genitourinary tract are entered under controlled conditions, without unusual contamination; or an otherwise clean wound into which a drain is placed.

(3) Contaminated procedure: open, fresh accidental wounds; procedures in which gastrointestinal contents or infected urine is spilled; or a major break in aseptic technique occurs. 
(4) Dirty procedure: old traumatic wounds with purulent discharge, devitalized tissue or foreign bodies; procedures in which a viscus is perforated or fecal contamination occurs. ${ }^{31,40,41,52,53}$

For the overall infection rate, a strong relationship exists between the escalating wound classification and subsequent SSI. In small animal surgery, clean surgery has a reported infection rate as low as $1.3 \%$ whereas the infection rate for dirty surgery is as high as $40 \%{ }^{26}$ The SSI rate was reported to be even higher for large animal surgery. An SSI rate of 8.3\% for clean surgery and 52\% for clean-contaminated procedures was reported for equine orthopedic procedures. ${ }^{24}$

The reported infection rate among orthopedic procedures varies. $25,38,39,45-48$ TPLO procedure has a higher reported infection rate than orthopedic procedures. ${ }^{45}$ Other procedural factors that are reportedly associated with an increase in SSI among veterinary patients are prolonged anesthesia time and surgery time ${ }^{37,41}$, use of non-locking implants in TPLO procedures ${ }^{46}$, and lack of appropriate perioperative antibiotics. $^{45}$

Studies in human medicine with regard to procedural risk factors have shown similar results to those of veterinary studies. However, drain placement and early suture removal have been reported to be associated with increased SSI rates only in human medicine. $33,53,54$ 


\subsubsection{Patient characteristics}

Patient characteristics such as pre-existing disease status and pathogenic bacteria colonization are potential risk factors for SSI. Risk factors identified in human studies include - but are not limited to - diabetes, cigarette smoking and obesity. ${ }^{33}$ Separate from its association with diabetes, obesity poses an independent risk for SSI. Cigarette smoking interferes with primary wound healing, possibly as a secondary result from constriction of peripheral blood vessels, leading to tissue hypovolemic and hypoxia. ${ }^{29}$

Among small animal surgical patients, obesity and intactness in males were identified as risk factors for SSI, and endocrinopathy was associated with an 8.2-fold increase in the likelihood of developing SSI. ${ }^{41}$ Among horses, animals with heavier body weight and increased pack-cell volume were significantly more likely to develop SSI after laparotomy. ${ }^{28}$

Colonization by multi-drug resistant pathogens has gained substantial research interest in recent decades. Methicillin-resistant Staphylococcus pseudintermedius colonization is associated with an increase in SSI after TPLO surgery in canine patients. ${ }^{55}$ Staphylococcus aureus colonization, found in the nostrils of $20 \%$ to $30 \%$ of healthy humans, has been strongly implicated as a predictor of SSI involving $S$. aureus. Human patients colonized with methicillin-resistant S. aureus (MRSA) are 9 to 12 times more likely to develop MRSA SSI after soft tissue surgery ${ }^{56,57}$ and 10 times more likely to develop MRSA SSI after orthopedic surgery. ${ }^{58}$ 


\subsubsection{Environmental factors}

Environmental factors include the hospital environment and the patient's own skin environment. The hospital environment can be a source for the acquisition and spread of pathogens. Pathogens such as Staphylococcus. aureus, Enterococcus species, Acinetobacter species and Clostridium difficile can survive on environmental surfaces for weeks or months. ${ }^{12,59,60}$ These pathogens can be transferred from patient to patient, from hospital staff to patient or vice versa, and from environmental surfaces to the patient or hospital staff. Several studies have also identified the airborne route as a significant exogenous source for intraoperative surgical wound contamination. ${ }^{61,62}$ The presence of many people in the operating room is also reportedly associated with SSI contagion. ${ }^{63}$

Bacterial colonies on the skin of health care personnel can be a source of SSI. Three principal types of skin floras have been described as present on human skin, namely resident flora, transient flora and infectious flora. ${ }^{64,65}$ The resident flora, such as Staphylococcus epidermis and Staphylococcus hominis, are often found on the surface of the skin or under the superficial cells of stratus corneum. ${ }^{66,67}$ These bacteria are usually non-pathogenic but may cause infection in sterile body cavities, in the eyes or in non-intact skin. Unlike resident flora, the transient skin flora - such as Staphylococcus warneri - are found on skin only occasionally. They survive on the skin and are occasionally pathogenic. ${ }^{64,68}$ Infectious flora include bacteria commonly isolated from abscesses, such as $S$. aureus or beta-hemolytic streptococci. The infectious floras are highly virulent and often cause disease ${ }^{69,70}$, although they are usually present on human skin only transiently. However, it has been reported that 
the hands of about $36 \%$ of doctors and about $18 \%$ of nurses in human hospitals are colonized with S. aureus. ${ }^{71,72}$

The most common transient and infectious flora on the hands of hospital personnel, which may lead to nosocomial infection, include S. aureus, Enterococcus spp., Escherichia coli, Pseudomonas aeruginosa and Clostridium difficile. Clostridium difficile, a spore-forming bacteria, is less commonly observed in SSI but commonly seen in nosocomial infections with gastrointestinal manifestation. Bacillus cereus has been reported to cause nosocomial infection in human neonatal intensive care units. ${ }^{73-75}$

The dynamic relationship between the size of bacterial inoculum, the virulence of the bacteria and the resistance of the host can help to explain the inherent risk of SSI. ${ }^{17}$ The relationship can be depicted as follows:

\section{Risk of infection $=$ Contamination $\times$ Virulence $/$ Host Resistance}

This equation may be an over-simplification of the risk factors for SSI, but it is useful when considering pathophysiology or prevention. Any bacteria, when present in a large amount (increased contamination), or in a small amount but with high virulence, or present in patients who are immune-compromised (decreased host resistance), can potentially cause SSI.

\subsection{Strategies for preventing SSI}

Owing to the morbidity and expense associated with SSI, preventative strategies are strongly emphasized. In human medicine the recommended guidelines are 
thorough, in the hope of targeting procedural, patient and environmental factors. ${ }^{35}$ Such guidelines have been adapted to veterinary medicine; they include patient and staff preparation and proper operation-room behavior. ${ }^{76-78}$ However, few of these guidelines have been validated in the veterinary environment. They are discussed in the following sections.

\subsubsection{Patient preparation}

Prior to surgery, the patient should be evaluated for pre-existing bacterial infection or systemic disease. If possible the surgery should be postponed pending resolution of any infection or systemic disease.17,76

The skin around the incision site should be properly prepared before surgery. The goals of surgical site preparation are mechanical removal of hair, dirt and oil; reduction of transient and infectious bacteria (such as S. aureus, S.pseudintermedius, E. coli, Streptococcus spp, Enterobacter spp and Clostridium spp); and decreasing the residual resident bacterial populations (such as Staphylococcus epidermidis, Corynebacterium spp and Pityrosporum spp).

In both veterinary and human medicine, it is recommended that the hair be removed by clipping, as studies have shown that the SSI rate increased if hair was removed by shaving. ${ }^{79} 35,74$ The timing of such hair removal is debated. In one veterinary study, the removal of fur before the induction of anesthesia was associated with a significantly higher superficial skin infection rate than removing fur immediately before surgery. ${ }^{37}$ Other studies have found no significant difference. ${ }^{23}$ Similar conflicting results have been reported in human studies.64,67,80,81 82 
After hair removal, the patient's skin is thoroughly washed and a final aseptic skin preparation is performed using an appropriate antiseptic agent. An ideal chemical agent to reduce the microbes on the skin should kill all skin organisms, have good residual effect, and be non-toxic and hypoallergenic. ${ }^{9}$ It should not result in significant systemic absorption of the chemical ingredients. ${ }^{9}$

\subsubsection{Surgery staff preparation}

\subsubsection{Surgical attire}

Current practices with regard to attire for surgical personnel include scrub suits, proper masks and head covers, and proper shoe covers and shoes. This "uniform" is designed to protect surgical personnel from exposure to body fluids and to maintain a clean surgical area. The attire has remained relatively unchanged over the past 50 years and is strictly regulated. ${ }^{35}$

Surgical scrub suits should be made of a tightly woven material. Bacteria are dispersed on epithelial cells that break into fragments of approximately $20 \mu \mathrm{m}$. Standard cotton fabric has a pore size of roughly $80 \mu \mathrm{m}$ to $100 \mu \mathrm{m}$, which is too spacious to provide a barrier to bacterial shedding; therefore, cotton-polyester materials are recommended. ${ }^{16,20}$ Although no study has shown a relationship between the use of scrubs and the incidence of SSI, the human medical guidelines still recommend that medical personnel should wear a designated short-sleeve, twopiece pant scrub suit in surgery, with the shirt tucked into the pants. ${ }^{80}$ Veterinary surgery textbooks recommend the same attire..$^{20}$ 
Masks are made of lint-free material containing a hydrophilic filter web sandwiched between two outer layers. The main function of surgical masks is to filter and contain aerosolized droplets of microorganisms expelled from the mouth and nasopharynx of surgical personnel during talking, sneezing and coughing. Masks should be worn whenever entering a sterile area, must be fitted over the mouth and nose, and must be secured in a manner that prevents venting. ${ }^{12,20,83}$ Studies have indicated that wearing masks in the operating room simply redirects the projectile effects of talking and breathing to the side of the masks. ${ }^{19,31,84}$ Therefore, although CFU counts may be reduced directly in front of the mouth, the overall operating room CFU counts are unaffected by the use of surgical masks. ${ }^{85-87}$ Clinical studies have shown that the SSI rate did not increase when non-scrubbed operating room personnel did not wear a mask. Nonetheless, current regulations and universal precautions require facemasks as part of the personal protective equipment for scrubbed personnel. ${ }^{32,66,88-90}$

Head covers such as caps are recommended.20,32,66,89 The hair of surgical personnel can carry pathogenic organisms such as $S$. aureus ${ }^{35,91}$, and infection outbreaks have also been reported to be associated with organisms carried on the hair. ${ }^{92,93}$ Human studies have failed to show significant differences in environmental contamination measured by CFUs among types of head covering. ${ }^{52,54,63,69}$ Therefore, a regular hair net may be sufficient.

Sterile surgical gloves should be worn during surgery. Sir William Halsted is credited with developing rubber gloves for use in the operating room. The infection 
rate in his hernia repair surgeries dropped from $9.6 \%$ to $1.8 \%$ after he introduced the use of surgical gloves. ${ }^{85}$ Surgical gloves should be used in conjunction with meticulous sterile techniques, as the gloves can be perforated during the course of surgery, leading to transfer of pathogens. Studies have shown that at least one glove became defective in $23.3 \%$ of small animal surgical procedures ${ }^{3}, 66 \%$ of large animal surgical procedures and roughly $10 \%$ in human general surgery procedures. $3,4,59,66,92,94$ Overall, wearing surgical gloves helps to decrease the infection rate and can serve as a method of self-protection against body fluid exposure; however, gloves cannot replace proper hand preparation before surgery.

\subsubsection{Hand preparation for surgery}

Glove perforation occurs in approximately a quarter of small animal surgeries. It is more likely to occur during non-soft tissue procedures, in gloves that are worn on the non-dominant hand, and during procedures lasting longer than $60 \mathrm{~min} .3,94$ Individuals who perform the surgery typically are unable to accurately detect the presence of a glove perforation ${ }^{3,66,92}$; therefore, the hand bacterial count must be as low as possible before the surgical gloves are donned.

Ignaz Semmelweis first recognized the relationship between hospital-acquired disease and the hand hygiene of health-care personnel in the 1850s. He recommended hand washing before examining the patients. ${ }^{76,89,95}$ Nearly two decades later, Joseph Lister introduced the concept of surgical antisepsis, and by the end of the $19^{\text {th }}$ century the concept of hand sanitization was widely accepted. At the 
time, chlorinated lime and carbonic acid were used for surgical hand preparations. ${ }^{69,96}$

The standard surgical hand preparation method has evolved gradually. The ideal method should be quick, effective, non-irritating and cost-effective. ${ }^{9}$ Researchers and manufacturers strive to find an ideal method and product for hand preparation, and there has been a tremendous amount of research in this area. The detail of that research is discussed in the following sections.

\subsection{Products for hand preparation before surgery}

The aims of surgical hand preparation are as follows: mechanical removal of dirt and oil, reduction of transient bacterial population, and persistent depression of the resident bacterial population. Pre-surgical hand preparation has dramatically reduced the SSI rate and continues to be necessary even after the adoption of sterile surgical gloves. An ideal antiseptic agent would be fast-acting, persistent (effective

for minutes to hours), cumulative (repeated exposure inhibits bacterial growth for a number of days), have a broad spectrum of activity, and be safe to use. ${ }^{5,97}$ Two types of antiseptic solutions are available for surgical hand preparation: aqueous scrubs and ABRs.

\subsubsection{Aqueous scrubs}

Aqueous scrubs use a water-based solution that contains active ingredients; the carbonic acid recommended by Joseph Lister was a form of aqueous scrub. ${ }^{6,7}$ Disinfecting the hands with aqueous scrubs requires performing a "surgical scrub". The scrubbing process involves first wetting the hands and arms with water, then 
applying solutions using the hands, sponges, or brushes; and finally rinsing the hands and forearms under water. Several types of aqueous scrubs - including phenolic compounds, iodine-based compounds and chlorhexidine $(\mathrm{CH})$ - are discussed here.

\subsubsection{Phenolic compounds}

Phenolic compounds induce progressive leakage of intracellular constituents and damage the bacterial membrane. ${ }^{85}$ The most commonly used phenolic compounds for surgical hand preparation are hexachlorophene and triclosan. Hexachlorophene has a high rate of dermal absorption, and toxic effects in neonates have been documented; its use is therefore limited. ${ }^{35,98}$ Triclosan inhibits Staphylococcus spp., Enterobacter spp. and a wide range of gram-negative intestinal and skin flora. ${ }^{84,99}$ However, many strains of Pseudomonas, Mycobacterium tuberculosis and fungi are resistant to triclosan.7,35,66,85,89,100-104

\subsubsection{Iodine-based hand scrubs}

Iodine-based hand antiseptics are effective against a wide range of gram-positive and gram-negative organisms, tubercle bacillus, fungi and viruses; they are also sporicidal.88-90,105 The mechanism of action is microbial cell death through oxidation after penetration of the cell wall..$^{35,98}$

Iodine has been replaced by iodophors because the use of iodine is associated with skin irritation and discoloring. Iodophors release iodine at a slower rate and therefore have longer activity than iodine. Povidone iodine (PI) is a combination of iodophors (polyvinylpyrrolidone, PVP) and can be prepared as an aqueous or 
alcohol preparation. ${ }^{85,101,102,104,106}$ However, PI may be inactivated by blood or serum proteins. Systemic absorption of iodine can occur and in rare cases has led to iodine toxicosis, but this is usually not a concern when it is used as a surgical hand scrub. ${ }^{7}$ The use of PI as an aqueous hand scrub agent has fallen out of favor due to its skin-staining effect and high incidence of contact dermatitis, which other available agents do not induce. In addition, PI allows faster bacterial regrowth than does chlorhexidine. ${ }^{69,107}$

\subsubsection{Chlorhexidine hand scrubs}

Chlorhexidine is a cationic biguanide that binds to negatively charged bacterial cell walls, altering the bacterial osmotic equilibrium, which at high concentrations results in cell death. ${ }^{63,108}$ It was first introduced as an antimicrobial agent in 1954, and exists as either acetate, gluconate or hydrochloride salts. ${ }^{85,101,102,104,106}$

Similar to iodine-based preparations, $\mathrm{CH}$ is commercially available in aqueous or alcohol formulations. It displays broad activity against gram-positive and gramnegative bacteria, anaerobes, yeasts and some lipid-enveloped viruses. Fungal coverage is reduced compared with that provided by solutions that are iodophorbased or alcohol-based. ${ }^{63,65}$ The activity of $\mathrm{CH}$ against bacterial spores has been described as sporistatic rather than sporicidal.88,106

Resistance to $\mathrm{CH}$ and other biocides has been observed in strains of S. aureus and P. aeruginosa, with genetic linkage through plasmid encoding. ${ }^{66,109}$ Unlike iodophorbased preparations, $\mathrm{CH}$ is not inactivated by blood or serum proteins. Furthermore, it binds to the stratum corneum and displays persistent activity. $66,92,110$ 


\subsubsection{Alcohol-based rubs}

Alcohol denatures and coagulates proteins, causes rapid lysis of cell walls, and disrupts cellular metabolism. ${ }^{95}$ Its effectiveness is contingent on concentrations rather than on the type of alcohol used..$^{71,89,111}$ The three main alcohols used in medical settings are ethanol, isopropanol and n-propanol. The preparations are typically available in concentrations of $60 \%$ to $90 \%$. Alcohol reduces the bacterial count on hands rapidly and is effective against a wide range of gram-positive and gram-negative bacteria, M. tuberculosis, and many fungi and viruses. ${ }^{63,65}$ It displays poor activity against bacterial spores, protozoan cysts and non-enveloped viruses. ${ }^{69,92}$ Alcohol does not remove surface dirt, and once evaporated it has no persistent antimicrobial effect.7,109,112 Alcohol can be combined with either iodine or $\mathrm{CH}$ in surgical preparations, which take advantage of its rapid bacteria-killing properties compared with aqueous preparations. ${ }^{68,113,114}$

\subsubsection{Selection of surgical hand preparation products}

No uniformly accepted criteria exist for selecting a specific surgical hand preparation product. In general, an appropriate product should be effective, fastacting, persistent, cumulative, safe, gentle to skin and cost-effective. ${ }^{9}$ The most commonly used products for surgical hand preparation are aqueous scrubs that contain $\mathrm{CH}$ soap and $\mathrm{ABRs}{ }^{7}$

\subsubsection{Aqueous scrubs}

Povidone iodine and $\mathrm{CH}$ are the most commonly used aqueous scrubs and both have proven efficacy. However, the potential contamination of tap water as well as 
faucets and scrub sinks may be a cause for concern regarding aqueous scrubs. ${ }^{97}$ Faucet aerators contaminated with gram-negative bacteria have reportedly been a direct cause of nosocomial infection in human intensive care units. ${ }^{73}$

Although SSIs clearly linked to water contamination have not been reported, it is recommended that the concentration of free chloride in the water should be maintained at over $0.1 \mathrm{ppm} .{ }^{97}$ In addition, the faucet aerator should be removed, and the water and faucet should be checked periodically for bacterial contamination. $\cdot^{97,114}$

\subsubsection{Hand rubs containing alcohol and other active ingredients}

Alcohol-based hand rubs (ABRs) and alcohol hand rubs that contain additional active ingredients are recommended if the quality of water cannot be assured. This is especially important in developing countries. ${ }^{14,99}$ Several hand rub products for surgical preparation are available on the market. The most popular product is a mixture of 30\% 1-propanol and 45\% 2-propanol solution (MPS) (Sterilium®, BODE Chemie GmbH \& Co. KG, Hamburg, Germany) with mecetronium ethylsulfate, glycerol, tereadecanol, fragrances and purified water being added for emollient effects. Another product that is available in Canada has 70\% 2-propanol solution as the active ingredient (IPS) (Manorapid®, Antiseptica Chem.Pharm. Produkte GmbH, Pulheim, Germany)99,98,115, with butandiol and lanolinpoly (oxyethylane) added for emollient effects. In the US, a solution consisting of $61 \%$ ethanol with $1 \% \mathrm{CH}$ gluconate $(E S / C H)$ is another popular product (Avagard $®$, 3M, Saint Paul, MN). 
The selection of scrub or rub techniques and the choice of a product should be based on the available results of efficacy testing, the nature of the medical practice, cost, and other factors such as staff acceptance and compliance. Most guidelines recognize both $\mathrm{CH}$ aqueous scrub and alcohol-based rubs as acceptable surgical hand preparation products. ${ }^{7,116}$

\subsection{Comparison of pre-surgical hand preparation methods}

\subsubsection{Steps before starting surgical hand preparation}

\subsubsection{Removal of artificial nails or nail polish}

Artificial nails or nail polish should be removed before medical personnel prepare their hands before surgery.7,35,103 The influence of nail polish on hand CFU has been examined using aqueous scrubs only and not with ABRs. Some studies have shown that no differences exist between bacterial counts on hands that do or do not have nail polish, after regular hand-washing and after surgical handscrubbing with 4\% CH. ${ }^{100,105,107,108,117,118}$ However, chipped nail polish and nail polish worn longer than four days was associated with increased bacteria counts on the fingernails of operation room nurses, even after a 5-min aqueous scrub with $\mathrm{CH}$. 12,99 Health-care workers who wear artificial fingernails are more likely to have a pathogen isolated from their hands compared to those do not wear artificial fingernails; moreover, these pathogens are resistant to removal either by alcoholbased gel or by antimicrobial soaps. ${ }^{119}$ In addition, higher positive culture rates of

gram-negative rods were observed among nurses who wore artificial nails. ${ }^{101,102,120}$ 
For these reasons, most surgical guidelines prohibit the use of any nail polish or artificial nails on the hands of the surgical team members.7,35

\subsubsection{Jewelry and watches}

Wearing a smooth band wedding ring does not increase the total count of hand bacteria but might increase Enterobacteriae carriage. 107,108 To date, no studies have examined the relationship between the wearing of complex jewelry or watches and post-surgical bacterial counts in hands that were prepared before surgery. This lack of research interest might be due to the logical assumption that complex jewelry would increase glove perforation rates. Current surgical guidelines recommend that all jewelry and watches should be removed before surgical hand preparation. ${ }^{110,121}$

\subsubsection{Use of nail pick and nail brush}

Subungual bacteria contributed three to four logarithms of the total hand bacterial count ${ }^{119}$, the use of nail picks or nail brushes prior to hand preparation for surgery is therefore recommended.7,120 However, in two studies performed in clinical setting, no additional protective effects were observed when nail picks or nail brushes were used together with a $\mathrm{CH}$ aqueous soap hand preparation. ${ }^{122,123}$ The effects of a nail brush or nail pick have not been evaluated when ABRs are used for surgical hand preparation.

\subsubsection{Regular hand wash and drying}

The hands must be free of soil and organic matter prior to surgical hand preparation. Regular hand wash with a neutral soap and cleaning of the subungual area is necessary before entering the operation room..$^{7,35,112}$ However, if the hands 
are not visibly soiled, a routine hand wash prior to surgical hand preparation might not be necessary. Wet hands increase the risk of glove perforation and decrease the antibacterial activity of ABRs. Therefore, the hands must be properly dried with sterile towels after an aqueous scrub, or air-dried after using ABRs, before donning the gloves. 7,124

\subsubsection{Application techniques}

\subsubsection{Aqueous scrub}

The use of brushes during scrubbing is discouraged in human medicine. ${ }^{7}$ It is recognized that surgical hand preparation performed with a sponge reduces the hand bacteria count as effectively as scrubbing with a brush but with less skin irritation. ${ }^{7,112,125}$ A randomized controlled clinical trial failed to demonstrate an additional antimicrobial effect of using a brush. ${ }^{126}$ In veterinary medicine, it is still common practice to use brushes while scrubbing, especially for large animal surgery. ${ }^{15}$ Further research is needed to conclude definitively whether surgical hand preparation using just a sponge is as effective as using a brush, among veterinary surgeons.

\subsubsection{Alcohol-based rubs}

Application techniques for ABRs have not been standardized. Various manufacturers provide similar but slightly different recommendations for each product. To the author's knowledge, no published studies have compared the efficacy of application methods. The WHO recommends six basic steps for hand hygiene, with an additional step for forearm application: ${ }^{7}$ 
(1) The hands should be completely dry prior to application.

(2) Start timing, the total duration of application should be based on manufacturer recommendation. Put approximately $5 \mathrm{ml}$ of rub solution into the palm of left hand. Dip the fingers of the right hand into the hand rub to decontaminate under the nails. Smear the hand rub on the right forearm, up to the elbow.

(3) Repeat the process by putting the solution into the palm of the right hand, and dip the fingers of the left hand and smear on the left forearm up to the elbow.

(4) Put approximately $5 \mathrm{ml}$ in the palm of the left hand.

(5) Cover the whole surface of both hands up to the wrist with solution, rubbing palm against palm with a rotational movement.

(6) Rub the hands using the following order: back of hand with opposite palm, palms and interdigital area with fingers interlinked, the back of the fingers, thumbs. Use more solution if necessary.

(7) Wait until the hands are dry before putting on surgical gloves and gown.

(Figure 1) 


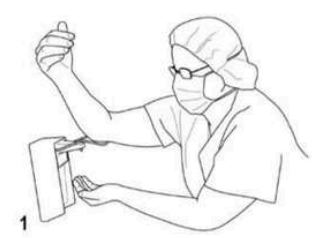

Put approximately $5 \mathrm{ml}(3$ doses) of alcohol-based handrub in the palm other arm to operate the dispenser

Dip the fing ips of your rigt Dip the fingertips of your right hand in nails ( 5 seconds) Ensure that the whote sin covered by using circular movements has fully evaporated (10-15 seconds)

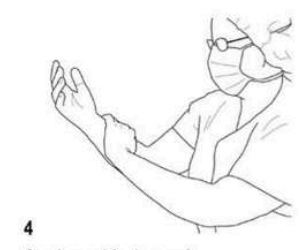

See legend for Image 3

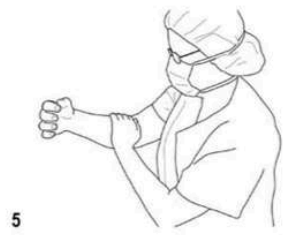

See legend for Image 3

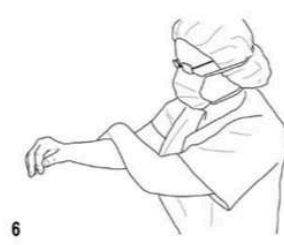

See legend for Image 3

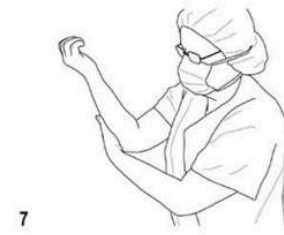

See legend for Image 3

Dip the fingertips of your left hand in

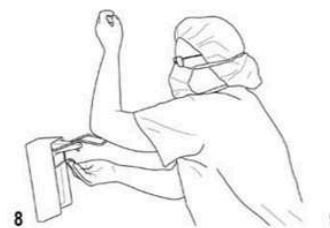
Put approximately $5 \mathrm{ml}$ ( 3 doses) of
alcohol-based handrub in the palm of your right hand, using the elbow of your other arm to operate the dispenser
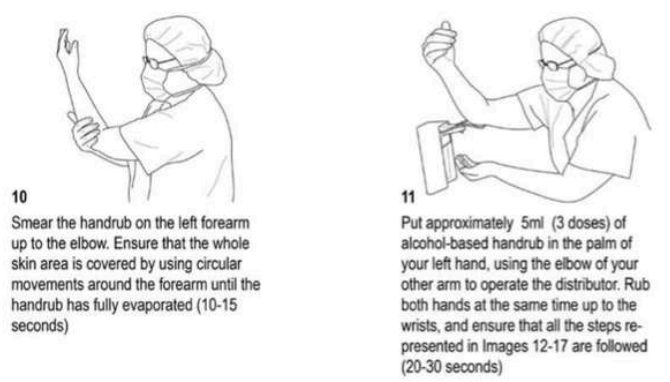
handrub docontaminate under the nails (5 seconds)

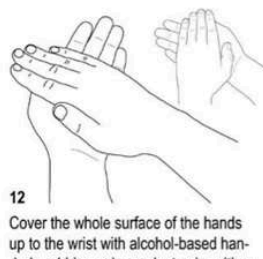

Cover the whole surface of the hands up to the wist with alconhi-based han-
drut, rubbing palm against palm with a

( Rub the back of the left hand, induding the wist, moving the right pal
and forth, and vice vers

Rub palm against palm back and forth drub, rubbing pa
rotating moveme
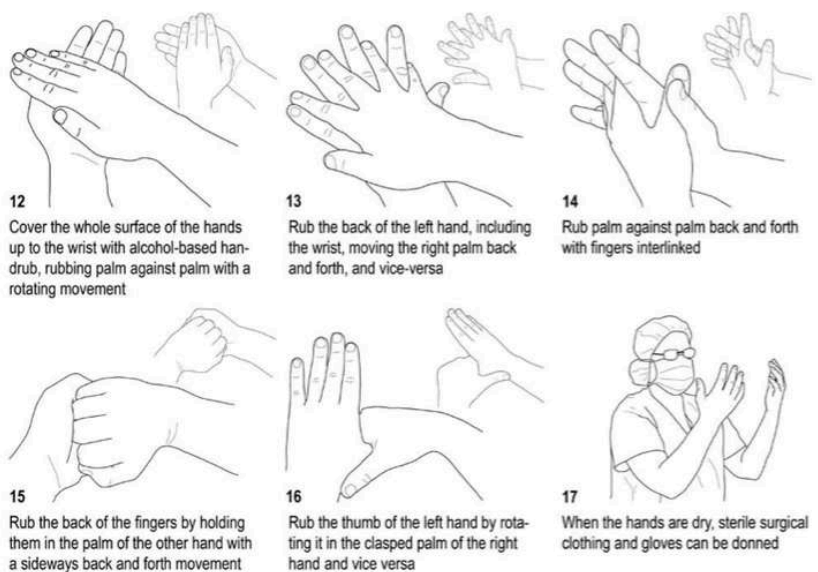

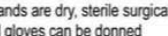
them in the palm of the other hand with land and vice vers

Figure 1 Surgical hand preparation technique with an alcohol-based hand rub formulation.

Copied from the WHO Guidelines on Hand Hygiene in Health Care. ${ }^{7}$ 


\subsubsection{Application time}

\subsubsection{Aqueous scrub}

A 10-min pre-operative aqueous scrub was the recommended practice for decades. The main concern about such a long period of scrubbing is the potential for damaging the skin. Damage to the barrier function of the stratum corneum increases the risk of colonization by pathogenic bacteria species. A long scrubbing time also leads to skin irritation and is often not properly complied with. ${ }^{109,112,127}$

Several studies have shown that scrubbing for 5 min reduces bacterial counts as effectively as a 10-min scrub. ${ }^{113,114,128}$ In addition, in surgical procedures that last longer than $90 \mathrm{~min}$, hand bacterial counts at the end of surgery were significantly higher for a 10-min scrub group than for a 5-min scrub group. ${ }^{14,113,129}$ Further studies also found a 3 -min scrub to be as effective as a 5-min scrub. ${ }^{111,130}$ Another study showed that a 3-min scrub reduced the bacterial count better than a 2-min scrub. However, the mean difference in bacterial count reduction was less than 0.5 $\log \mathrm{CFU} / \mathrm{ml}$ and was considered to be clinically insignificant. ${ }^{131}$

The time needed for subsequent scrubs after the first surgery on the same day has also been investigated. A study evaluating 2-min, 4-min and 6-min subsequent scrubs using $4 \% \mathrm{CH}$ showed that scrubbing for 4 min or 6 min did not provide any advantage over scrubbing for $2 \mathrm{~min}$; therefore, the researchers recommended a 4min scrub for the surgical team's first procedure, and a 2-min scrub for subsequent procedures. ${ }^{114}$ Another study compared a 5-min initial plus 3-min subsequent scrub 
with a 3-min initial plus 30 -sec subsequent scrub, using $4 \%$ CH. ${ }^{112}$ There was no difference in bacterial count between the two groups, either immediately and at $2 \mathrm{~h}$ after the initial scrub. However, the 30-sec subsequent scrub was less effective for bacterial count reduction compared with the 3 -min subsequent scrub. ${ }^{112}$ The efficacy of a 5-min initial scrub plus a 3.5-min subsequent scrub, versus a 3-min initial plus a 2.5-min subsequent scrub, using $4 \% \mathrm{CH}$ was also compared. ${ }^{132}$ There was no significant difference in bacterial count between these two protocols, either immediately or $2 \mathrm{~h}$ after the surgical hand scrub. ${ }^{132}$ In conclusion, the current literature from human medicine supports the protocol of 2 to 3 min of contact time for the initial scrub, and 2 min of contact time for subsequent scrubs, when a $4 \% \mathrm{CH}$ aqueous scrub method is used for surgical hand preparation.

\subsubsection{Alcohol-based rubs}

Surgical hand antisepsis using an ethanol solution requires an application time of at least 3 min to fulfill the European standard for surgical hand preparation. ${ }^{116}$ An application time of less than 3 min has been evaluated for an MPS solution; the results showed that a 90-sec rub could be as effective in bacterial reduction as a 3min rub for both healthy volunteers and health care personnel.14,117 One study reported similar results when ethanol was used for surgical hand preparation. ${ }^{115}$ No studies have evaluated the effect of contact time on efficacy for an ES/CH solution.

In conclusion, the required application time for surgical hand preparation using ABR varies and depends on the product being used. However, the application time should be at least $90 \mathrm{sec}$ when isopropanol or ethanol solutions are used. Most 
studies on application techniques for surgical hand preparation have involved healthy volunteers and human health care providers. Equivalent studies have not been conducted among veterinary caregivers.

\subsection{Evaluation of surgical hand preparation products}

\subsubsection{Infection rate}

The most effective and clinically relevant method for assessing surgical hand preparation products is to analyze the associated infection rates. However, due to the low infection rate ( $2 \%$ to $4 \%$ ) for routine clean and clean-contaminated surgery, around 4158 cases are needed to detect a $2 \%$ difference in infection rate at a $90 \%$ level of statistical power. ${ }^{133}$ One study used an equivalent cluster randomized crossover trial approach over a 16-month period, at six surgery centers, with a sample of 4387 consecutive clean and clean-contaminated surgeries. A 5-min aqueous scrub using either $4 \%$ PI (Betadine) or 4\% CHG (Hibiscrub®) was compared with a 5 -min hand rub using MPS. The infection rate was $2.48 \%$ in the scrub group and $2.44 \%$ in the hand rub group. The researchers concluded that both protocols were equally effective at preventing SSI.130,133 However, they observed that the hand rub protocol had significantly better compliance in terms of the recommended application time, which was two repetitions of $2.5 \mathrm{~min}$ of hand rubbing, compared with 5 min of hand scrubbing. ${ }^{133}$ A separate prospective study evaluated the use of ES/CH in pediatric urologic procedures and found no statistically significant differences in infection rate between the ES/CH group $(0.11 \%)$ and the $\mathrm{CH}$ scrub group $(0.17 \%) .{ }^{134} \mathrm{~A}$ similar study was conducted in a 
neurologic surgery environment and the researchers found no difference in infection rates between the ES/CH group and the traditional scrub group. ${ }^{135,136}$

A randomized trial was conducted in a Kenyan rural hospital, to compare the results of a hand wash for 4-5 min (washing with plain soap using clean tap water) versus a WHO-recommended alcohol-based hand rub solution (75\% isopropyl alcohol, $1.45 \%$ glycerol and $0.125 \%$ hydrogen peroxide). Among 3317 patients who underwent clean and clean-contaminated surgery, there was no significant difference in infection rates for plain soap (8\%) versus ABR (8.3\%).137

\subsubsection{Bacterial reduction}

Most researchers use hand bacterial count to evaluate antibacterial efficacy. The finger press method and the glove juice technique are two commonly used techniques for sample collection. The finger press method involves pressing the fingertips, knuckles or the whole palm against an agar plate; the plates are then incubated for $24 \mathrm{~h}$ to $48 \mathrm{~h}$. The amount of bacteria is recorded as colony-forming units (CFUs), which are counted from the agar plate. ${ }^{123,136,138-140}$ This method is relatively easier and faster than the glove juice technique (discussed below). However, it might not reflect actual hand bacterial counts, as the counts are dependent on the anatomic location, hand size and culture method or technique used.

The glove juice method has been used in several studies. $5,108,119,122,131 \mathrm{~A}$ combination of $0.075 \mathrm{~mol} / \mathrm{L}$ phosphate-buffered normal saline with $0.05 \%$ polysorbate 80 (Tween $80^{\mathrm{TM}}$ ) is the most commonly used standard sample collection 
fluid. The participants don sterile gloves and $20 \mathrm{ml}$ of fluid is infused into the glove in a sterile method. The gloved hands are then clutched and massaged gently for $30 \mathrm{sec}$ to $1 \mathrm{~min}$. The glove is removed and the fluid inside is used for culturing. The amount of bacteria on the hands is presented as $\mathrm{CFU} / \mathrm{ml}$ of the sampling fluid. This method is more time-consuming but reflects the bacterial count more accurately than the finger press method. ${ }^{140}$ The glove juice method is regarded as the standard test for the effectiveness of antiseptic solutions. ${ }^{121}$

Non-volatile agents, such as $\mathrm{CH}$, may remain on the samples collected by either the glove juice technique or the finger press method. The addition of a neutralizing agent to the standard sampling fluid has been suggested as a method of preventing false positives in efficacy assessment. ${ }^{141}$ However, the efficacy of neutralization is hard to evaluate, and residual neutralizing agent in the collection fluid could remain on the hands of participants and create a false negative in efficacy assessment.121 The US Food and Drug Administration (FDA) therefore suggests that when reporting the test results for surgical hand preparation products, researchers should clearly indicate whether a neutralizing agent was used or not, to allow readers to compare the results across different studies. ${ }^{121,129}$

Reductions in hand bacteria are tested at different time points to help evaluate the immediate and persistent (cumulative) efficacy. The FDA standard requires surgical hand preparation products to fulfil the following criteria for efficacy:

(1) a 1-log (base 10) reduction in microbial flora for each hand, relative to the baseline, within 1 min after the first surgical scrub procedure on Day 1; and 
continued suppression of bacterial growth on each hand to below-baseline levels at 6 h on Day 1.

(2) a 2-log (base 10) reduction of microbial flora on each hand within 1 min of the last scrub procedure on Day 2.

(3) a 3-log (base 10) reduction of the microbial flora on each hand within 1 min of the last scrub procedure on Day $5 .^{121}$

Unlike the FDA standard, the European standard does not require repeated efficacy testing. Only the immediate effects and the level of regrowth after the hands have been in gloves for $3 \mathrm{~h}$ are measured. The European standard requires the results of such testing to not be inferior to the reference $60 \% \mathrm{n}$-propanol solution at a contact time of 3 min. ${ }^{124}$

\subsubsection{Comparison among aqueous scrubs}

Compared with PI, CH might be more effective at reducing bacterial CFU. In a study of operating room nurses, researchers found that 3-min scrubs using $4 \% \mathrm{CH}$ achieved a significant lower CFU/ml compared with 7.5\% PI. ${ }^{142}$ Similarly, another study found that 4\% CH was significantly more effective than PI, both immediately and $2 \mathrm{~h}$ after the initial scrub and again $2 \mathrm{~h}$ after a subsequent scrub. ${ }^{132}$ This finding was the same for both an initial 5-min plus subsequent 3-min scrub and an initial 3min plus 30-sec subsequent scrub. ${ }^{132}$ Another study compared a 5-min aqueous

scrub using either $\mathrm{CH}$ and PI among surgeons working with large animals. ${ }^{143}$ There was no significant difference in hand bacterial counts, both immediately and $2 \mathrm{~h}$ 
after surgical hand preparation, between the groups that used $\mathrm{CH}$ or PI aqueous scrubs. ${ }^{143}$

\subsubsection{Comparison between aqueous scrub and alcohol-based rubs}

In one study, MPS was compared with PI or CH scrub, using the finger impression method and healthy volunteers. ${ }^{130}$ Samples were taken before and after surgical hand preparation, and every $2 \mathrm{~h}$ until the end of surgery. No significant differences were observed between MPS and 3-min scrub using PI or CH, with regard to CFU count and positive culture rates. ${ }^{130}$ In another randomized crossover trial using seventy-five surgeons at one hospital 4\% $\mathrm{CH}$ and hand rubbing using MPS were compared. ${ }^{129}$ One product was used for four weeks and then changed to the other product after a wash-out period. The bacterial count (CFU/ml) was measured before preparation, immediately after preparation and again after the surgical procedure. Rubbing with MPS was significantly more effective than scrubbing with $4 \% \mathrm{CH}$ with regard to reducing the bacterial count, both immediately after preparation and at the end of the surgical procedure. ${ }^{129}$ Another study compared ES/CH rub with a CH or PI 5-min surgical hand scrub among operating room nurses. A cotton swab was rolled along the fingers to obtain samples from all participants, and no significant differences were found in the positive culture rates. ${ }^{144}$

A veterinary medicine study was conducted among surgeons working with large animals, to evaluate three hand hygiene protocols after performing regular physical examination. ${ }^{135}$ The findings showed that hand washing with $0.3 \%$ triclosan soap was significantly more effective at reducing bacterial count compared with the use 
of $62 \%$ ethanol gel and ES/CH rub. ${ }^{135}$ This was an interesting finding in light of the literature from human medicine, in which most researchers agree that ABRs are at least as effective as hand washes for reducing bacterial count. ${ }^{140,145}$ The nature of a practice - human versus veterinary surgery - may result in differential contamination by transient bacteria. Veterinarians often perform oral examination, orthopedic examination and rectal examination, and they also restrain animals and clip their fur before surgery. Significantly higher hand bacterial counts were noted among large animal surgeons who were in contact with their patients immediately before they prepared for surgery, compared with those who were not. ${ }^{135}$ In conclusion, studies comparing the results for aqueous scrubs versus ABRs have shown that both surgical hand preparation methods reduce the hand bacterial count effectively.

\subsubsection{Comparison among alcohol-based rubs}

Several studies have compared the efficacy of different ABRs. There is no strong evidence to suggest that one commercial product is superior to another with regard to antibacterial activity. Some researchers have suggested that alcohol with additional active ingredients is superior to pure alcohol rubs, but this finding has not been consistently reported among studies. ${ }^{115,127,146}$

In one study comparing the efficacy of ES/CH, MPS, and 70\% ethanol solution (ES) among healthy volunteers, showed there was no difference immediately after application, but ES/CH provided significantly higher bacteria reduction $6 \mathrm{~h}$ after application. Another study compared ES/CH, zinc pyrithione in 70\% ethanol 
(Triseptin ${ }^{\mathrm{TM}}$ ) and 7.5\% PI scrub used by healthy volunteers. There was no significant difference in hand bacterial counts among groups using the three products after 3 min of application. All products meet the FDA standards at Day 1 and Day 2, but only Triseptin ${ }^{\mathrm{TM}}$ met the standard at Day $3 .{ }^{127}$ The antibacterial efficacy of a 3-min hand rub using ethanol at different concentrations among healthy volunteers was evaluated. ${ }^{145}$ Compared with the European standard solution (60\% propanol), ethanol at $85 \%$ was the only concentration that provided similar bacterial reduction. Solutions of 75\% ethanol and 95\% ethanol were significantly less effective immediately and $3 \mathrm{~h}$ after application, compared with the standard solution. ${ }^{145}$

Only one study has evaluated the efficacy of ABRs among small animal surgeons. A clinical trial was conducted with experienced surgeons, in which bacterial CFUs were evaluated through the finger press method. The results showed that aqueous $\mathrm{CH} / \mathrm{PI}$ and MPS rub had similar immediate effects, but the MPS rub had a significantly better sustained effect after a mean surgical time of 90 min..$^{140}$

\subsubsection{Evaluation of acceptance}

Alcohol-based rubs were the favored surgical hand preparation method, according to a survey among operating room nurses. ${ }^{69}$ Reasons for this preference might be the skin irritation and longer application time associated with traditional scrubs. Skin irritation is more frequently observed after surgical hand preparation with aqueous $\mathrm{CH}$ than with an $\mathrm{ABR}$ solution. ${ }^{133}$ This might be due either to the soapand-water washing process or to the brushing process. The water content on the dorsal surface of hospital nurse's hands decreased significantly during hand 
washing with soap and water, compared with ABR. ${ }^{147}$ Overall, ABR solutions

produce fewer skin reaction and less reported dry skin, and are better

tolerated. ${ }^{69,132,136}$

\subsubsection{Cost and safety}

Cost analyses have been performed to compare ABRs and aqueous scrubs for surgical hand preparation. The cost of purchasing products, the time needed for a staff member to perform surgical hand preparation, the water needed for the preparation, and the amount of solid waste produced were all taken into consideration. Aqueous scrubs are approximately three times more expensive than ABRs. ${ }^{69,148}$ One surgical hand preparation episode with aqueous scrub uses approximately $20 \mathrm{~L}$ of warm water, or $60 \mathrm{~L}$ (or more) for an entire surgical team. ${ }^{149}$ This is an important issue worldwide, particularly in countries or areas that have a limited safe water supply.

Alcohol-based rubs may incur potential management challenges. One of the biggest concerns is their flammability. Flash point is the minimum temperature at which a substance can be ignited by an open flame; the flash point for $82 \%, 70 \%$ and $60 \%$ isopropanol, propanol and ethanol is $21^{\circ}$ Celsius. ${ }^{71} \mathrm{~A}$ flash point below $21^{\circ} \mathrm{C}$ is considered easily flammable. ${ }^{71}$ Certain commercialized products have an even higher concentration and therefore a lower flash point. Nonetheless, the risk of fire is generally believed to be relatively low. One study reported that seven minor fire incidents associated with the use of ABR occurred during a total of 25038 hospitalyears. ${ }^{150}$ In a single reported fire incident in the US, alcohol gel was applied 
immediately before the removal of a polyester gown, and the static electricity ignited the alcohol.151

\subsection{Surgical hand preparations: unanswered questions}

Alcohol-based rubs and aqueous scrubs are both recommended by veterinary surgery textbooks. ${ }^{20}$ This recommendation is extrapolated from human literature, since only a small number of studies have been performed in the veterinary setting.

In a survey conducted in $2011,61.4 \%$ of veterinary surgeons were using aqueous scrub such as $\mathrm{CH}$ or PI, and $54.5 \%$ of veterinary surgeons were scrubbing for over 5 min. ${ }^{15}$ Most veterinary schools favor the aqueous scrub method; the author conducted a web-based survey to surgeons in 2014. Of the 31 veterinary schools in North America, 17 schools responded to the survey, it was observed that $75 \%$ of veterinary schools only teach the aqueous scrub $(4 \% \mathrm{CH})$ method in their junior surgery laboratories, and students are allowed to use only aqueous scrub $(4 \% \mathrm{CH})$ in 7 veterinary schools. These numbers stand in contrast to most recommendation guidelines in human medicine.7,101,102 A main factor is the small body of evidence that supports the short- and long-term efficacy of ABR in veterinary medicine. Based on research from human medicine, it seems reasonable to expect that veterinary medicine would adapt and switch to using ABRs. However, depending on the ABR manufacturer, different pre-treatment hand preparation, different application methods, and different contact times make teaching of an appropriate ABR-based hand preparation routine particularly challenging. There are also concerns that alcohol does not provide enough residual effect, although it 
has been claimed that adequate residual bacterial reduction could be achieved if the bacterial count immediately after surgical hand preparation is low. ${ }^{152}$

\subsubsection{Efficacy of aqueous scrub and ABR among veterinary students}

Most studies have involved healthy volunteers or experienced operating room nurses, surgeons or surgery residents. One might assume that such participants are well educated and experienced in the proper application of surgical hand preparation products. However, this might not be the case in veterinary clinical situations, and the efficacy of aqueous scrubs and ABRs used by veterinary students has not been evaluated. In surgical hand preparation, compliance does not seem to be a problem since it is a crucial step that each surgery team member has to perform without exception. However, the application method may be more prone to error when ABRs are used..$^{9}$ One study showed that students in the third and fourth years of medical school achieved significantly higher bacterial reduction compared with first- and second-year medical students when using ABR for hand hygiene. ${ }^{153}$ Structural training sessions - including lectures, practice and adding fluorescent dye to evaluate missed spots - could increase the efficacy of ABR for hand hygiene. ${ }^{153-155}$ In this study, we evaluated the efficacy of ABRs for surgical hand preparations among third-year veterinary students after a short instructional session.

\subsubsection{Optimal application time for ABR among veterinary students}

The WHO guidelines for hand hygiene recommend a standard application method, and suggest repeated standard application until the total manufacturer recommended contact time is achieved. ${ }^{7}$ The recommended application time for 
ABRs, unlike aqueous scrubs, differs for each product. For MPS an application time of $90 \mathrm{sec}$ is recommended, whereas for IPS the recommended application time is 3 min. The other two products available - one containing $70 \%$ ethanol with $5 \%$ isopropanol, and one with ES/CH - do not specify the time needed for application. The recommendations are based on in vivo testing by the relevant manufacturers, but the correct contact durations have not been thoroughly verified in clinical veterinary situations. We therefore wished to evaluate the standards for application time for ABRs.

\subsubsection{Selective efficacy of the alcohol based rubs}

A study involving large animal veterinary staff showed alcohol based hand sanitization to be less effective in bacterial reduction compared to aqueous triclosan soap and water hand wash. ${ }^{135}$ We suspect such result is due to the fact that alcohol based hand rubs are less effective at removing spore-forming bacteria comparing to soap and water hand wash. Furthermore, alcohol may actually serve as a selective agent for isolating spore-forming bacteria. ${ }^{12}$ No studies have evaluated the bacteria isolated from the hands of veterinarians and after surgical hand preparation. We wished to identify the bacteria and compare the culture rate before and after hand preparation using different protocols. 
3 MATERIALS AND METHODS 


\subsection{Materials and methods}

The study was approved by the University of Prince Edward Island Research Ethics and Biosafety Committees. A controlled randomized prospective study was conducted. Third-year veterinary students who were participating in junior surgery laboratories were included as research participants, and written consent was obtained from all participants prior to the study.

\subsubsection{Surgical hand preparation protocols}

Hand preparation procedures included hand scrubbing with non-abrasive aqueous scrubs containing $\mathrm{CH}$, and hand rubbing using MPS, IPS or ES/CH. Each procedure was carried out at three different contact times $(1.5 \mathrm{~min}, 3 \mathrm{~min}$, and 5 min) for a total of 12 possible procedure/time combinations. Using shuffled cards, participants were randomly assigned to four of the possible 12 combinations. A minimum of 7-day wash out period was allowed between each surgical hand preparation.

Detailed practical guidance on the steps for surgical hand preparation was given to all participants by the primary investigator, and illustrated instructions were posted next to the scrub sink in accordance with current practice standards and the WHO guidelines. ${ }^{7}$ Contact time was defined as the length of time during which hands and forearms were in contact with the tested products.

The hand-scrubbing procedure was performed as follows: (1) Wet hands and forearms with warm tap water. Use nail picks to clean under the fingernails. (2) Start timing; wet the sponge and squeeze to work up a lather, and make sure the 
lather is in contact with nails, cuticles, interdigital spaces, hands and forearms. (3) Scrub using the sponge side only to clean nails, cuticles, interdigital spaces, hands and forearms. (4) When the assigned contact time is reached, rinse hands and forearms thoroughly with tap water, and dry with a sterile towel before putting on surgical gloves and gown.

The hand-rubbing procedures were performed as follows: (1) Wash hands and arms with a neutral, non-medicated soap (Dermotan®, Antiseptica Chem.Pharm. Produkte GmbH, Pulheim, Germany) for $1 \mathrm{~min}$, and use nail picks to clean under the fingernails. (2) Dry hands with non-sterile paper towel. (3) Start timing. Place approximately $5 \mathrm{ml}$ (MPS or IPA) or 1 pump (ES/CH) into the palm of the left hand. Dip the fingers of the right hand into the hand rub to decontaminate under the nails. Smear the hand rub on the right forearm up to the elbow. (4) Repeat the process for the other hand: place the selected solution in the palm of the right hand and dip the fingers of the left hand, and smear onto the left forearm up to the elbow. (5) Place another $5 \mathrm{ml}$ (approx.) (MPS or IPS) or 1 pump (ES/CH) in the palm of the left hand. (6) Cover the whole surface of both hands up to the wrist with solution, rubbing palm against palm with a rotational movement. (7) Rub the hands in the following order: back of hand with opposite palm; palms and interdigital area with fingers interlinked; back of the fingers; thumbs. Use more solution if necessary. (8) Repeat steps 5 to 7 until the assigned contact time is reached. (9) Wait until the hands are dry before putting on surgical gloves and gown. 


\subsubsection{Sample collection}

Samples were obtained from participants using the glove juice technique as previously described. ${ }^{15}$ All participants donned sterile gloves (Triflex®, Cardinal Health, McGaw Park, IL) and then $20 \mathrm{ml}$ of $0.075 \mathrm{~mol} / \mathrm{L}$ phosphate-buffered normal saline with $0.05 \%$ Tween 80 was immediately instilled into the glove of the dominant hand sterilely. The solution was gently rubbed up and down the fingers of the glove. The participants then clenched their fists and shook their hands for $60 \mathrm{sec}$. Thereafter, the gloves on both hands were removed carefully without contaminating the hands and forearms, and $5 \mathrm{ml}$ to $10 \mathrm{ml}$ of the liquid inside each glove was removed sterilely using a syringe. The samples were collected before (PRE) and after (POST) surgical hand preparation. After POST sampling, the participant used a sterile towel to dry their hands, then donned a gown and fresh gloves to perform ovariohysterectomy (OHE) or castration on live animals, using standard aseptic techniques.

Samples were collected again from the gloves of participants after the end of surgery (END). All gloves used for sample collection in this study were tested for the presence of punctures by insufflation and visual inspection. Individual sample sets (PRE, POST and END) were excluded if contamination that required a glove change had occurred; if the glove failed the pressure leak test; if the participant did not provide samples for culture at all three collection time-points; or if the participant had a visible full thickness wound on the hands. Individual participants were excluded if an allergic reaction to a research product or latex developed during the 
study period. A minimum 7-day wash-out period between hand treatments was enforced to allow re-growth of the normal skin flora, as previously described. ${ }^{145}$

\subsubsection{Aerobic culture, bacterial count and bacterial isolation}

Samples collected were immediately cultured. Each sample was diluted by two serial 10 -fold dilutions using $0.075 \mathrm{~mol} / \mathrm{L}$ phosphate-buffered saline with $0.05 \%$ Tween 80 . Using a sterile micropipette, $0.1 \mathrm{ml}$ of each undiluted and serially diluted solution was inoculated onto sheep-blood agar plates, using sterile L-shaped hockey stick cell spreaders. The agar plates were then incubated for $48 \mathrm{~h}$ at $35{ }^{\circ} \mathrm{C}$ under aerobic conditions. The count of bacterial colony-forming units per $\mathrm{ml}(\mathrm{CFU} / \mathrm{ml})$ was calculated using direct counting methods, with a range of 0 to $300 \mathrm{CFU} / \mathrm{ml}$. Plates that yielded growth of over 300 colonies were excluded for CFU determination and individual colony isolation. The author counted all agar plates with no repetition. Bacterial $\log \mathrm{CFU}$ were determined, and reductions in $\log \mathrm{CFU}$ from the glove juice at the POST and END sampling time points were calculated by subtracting the $\log \mathrm{CFU}$ of POST or END from the $\log \mathrm{CFU}$ of PRE.

Based on gross appearance, individual colonies were further cultured onto a sheep-blood agar plate and incubated for $24 \mathrm{~h}$ at $35^{\circ} \mathrm{C}$ under aerobic conditions. The colonies were then examined for bacterial identification using matrix-assisted laser desorption ionization-time of flight mass spectrometry (MALDI Biotyper system, Bruker corporation, Billerica, MA). Bacteria identified were categorized as gram-positive, gram-negative, spore forming bacteria or coagulase-positive Staphylococcus spp. 


\subsection{Statistical analysis}

The POST and END bacteria $\log C F U$ reduction between groups was compared using multivariate analysis of variance (ANOVA). Hand preparation product, contact time and product/contact-time interaction was included in the models, with the participants included as a random effect. Surgery time, type of surgery (OHE or castration) and role in surgery (primary or assistant) were included as three variables in END $\log \mathrm{CFU}$ reduction. Stepwise backward elimination was performed to remove non-significant effects. A post-hoc analysis was performed using Tukey's honest significant difference tests, and "test slices" were used to test the effect of time for each product.

For each bacterial category, the culture status was classified as either positive or negative. The positive culture status among groups was compared using a multivariate logistic regression model. Product, contact time and product/contacttime interaction were used as main factors, and culture status from PRE samples was included as a confounding factor. For END samples, surgery type (OHE or castration) and role in surgery (primary or assistant) were also included in the model. Stepwise backward elimination was performed. A $P$-value of $\leq 0.05$ was considered statistically significant for all analyses. All statistical tests were performed using commercialized software (JMP 11®, SAS system, Cary, NC). 
4 RESULTS 


\subsection{Descriptive data}

Forty-seven third-year veterinary students were enrolled into the study. The data of two participants were excluded from the analysis because of their allergic reactions to $\mathrm{CH}$ products. In addition, 25 sample sets were excluded, nine due to contamination during surgery, eight due to removal of surgical glove prior to sample collection, and nine due to glove perforation (detected by the pressure test). A total of 155 sample sets (PRE, POST and END) from 45 students were included in the final bacterial analysis.

Of the 95 surgeries performed, 76 were OHEs and 19 were castrations. Surgery time ranged from 57 min to 255 min. One patient that underwent OHE developed SSI from which Staphylococcus pseudintermedius was cultured. This bacterial isolate was not cultured from the hands of either the primary or the assistant student.

\subsection{Aerobic bacterial reduction}

The student's role in surgery (primary or assistant) and the type of surgery (OHE or castration) did not exert significant effects on bacterial reduction. The type of hand preparation product, rather than the contact time, exerted a significant effect on POST logCFU reduction $(P<.001)$. Pair-wise comparison showed that at the manufacturer-recommended contact times, ES/CH and $\mathrm{CH}$ were more effective for $\log C F U$ reduction than MPS or IPS. For all hand preparation products tested, an 
increase in contact time did not affect the reduction in logCFU (Figure 2).

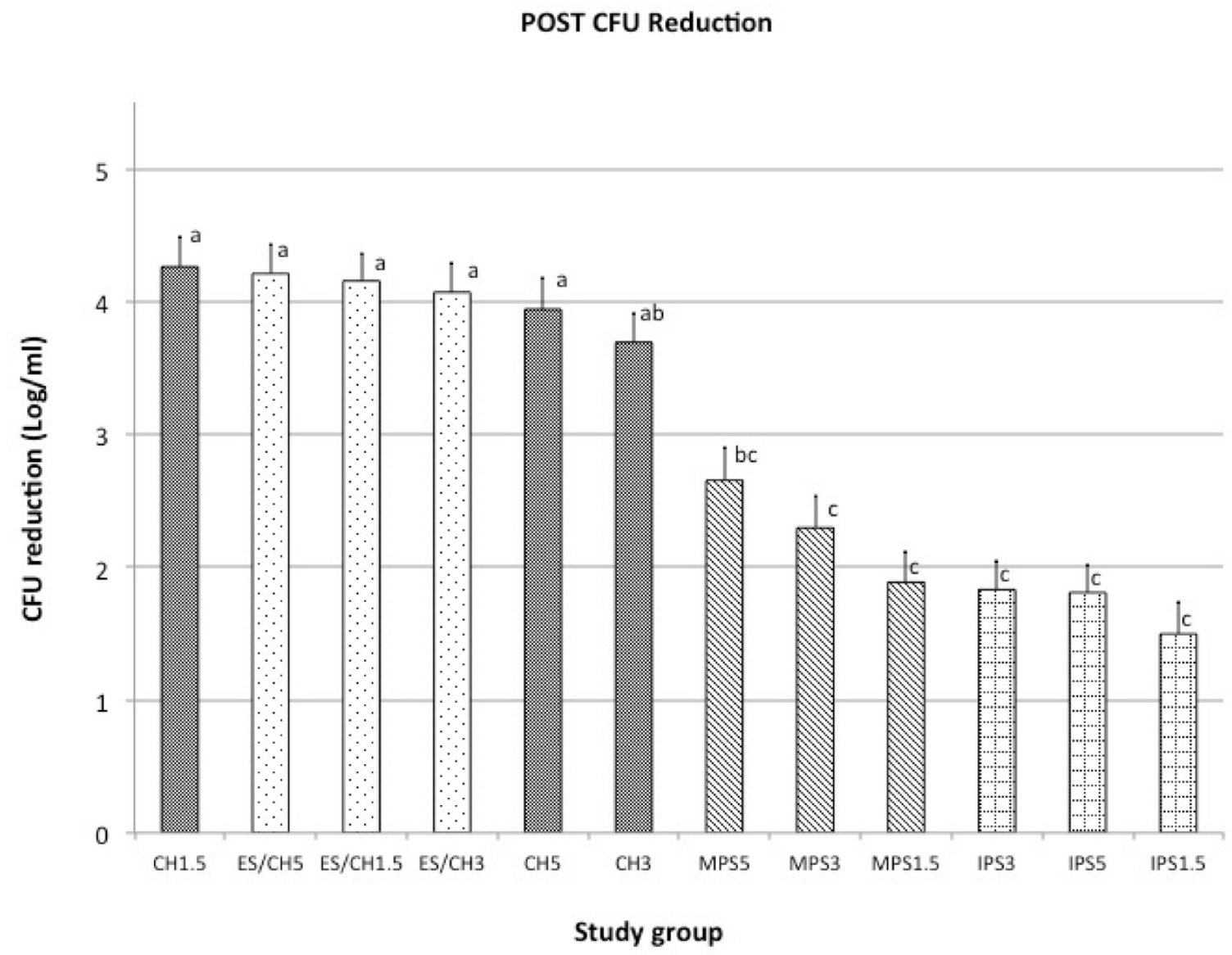

Figure 2 Mean $\log \mathrm{CFU}$ reduction immediately after surgical hand preparation (POST) using various products.

Key: CH: 4\% Chlorhexidine gluconate scrub; MPS: 30\% 1-propanol and 45\% 2propanol solution; IPS: 70\% 2-propanol solution; ES/CH: 61\% ethanol solution with $1 \%$ chlorhexidine gluconate. Contact times: $1.5 \mathrm{~min}, 3 \mathrm{~min}, 5 \mathrm{~min}$. Values with different lowercase letters $(a, b, c)$ next to the bars indicate significantly differences $(P<0.05)$. Each error bar is constructed using 1 standard deviation from the mean. 
For END samples, the hand preparation product, contact time and product/contact-time interaction all had significant effects on bacteria logCFU reduction $(P<0.001, P=0.023$, and $P=0.042$ respectively $)$. The ES $/ \mathrm{CH}$ application with 3-min and 5-min contact times achieved a significantly greater log CFU reduction compared with IPS application (all three contact times) and MPS (1.5-min and 3-min contact times). Comparison of the contact times showed that MPS and ES/CH applications lasting 5 min achieved a significantly greater log CFU/ml reduction than an application lasting 1.5 min (Figure 3). Thus, an increase in contact time significantly increased bacterial reduction in ES/CH and MPS groups $(P=0.003$ and $P=0.014$, respectively) at the end of surgery. At manufacturer-recommended contact times, the ES/CH group showed a significantly greater logCFU reduction compared with IPS. 


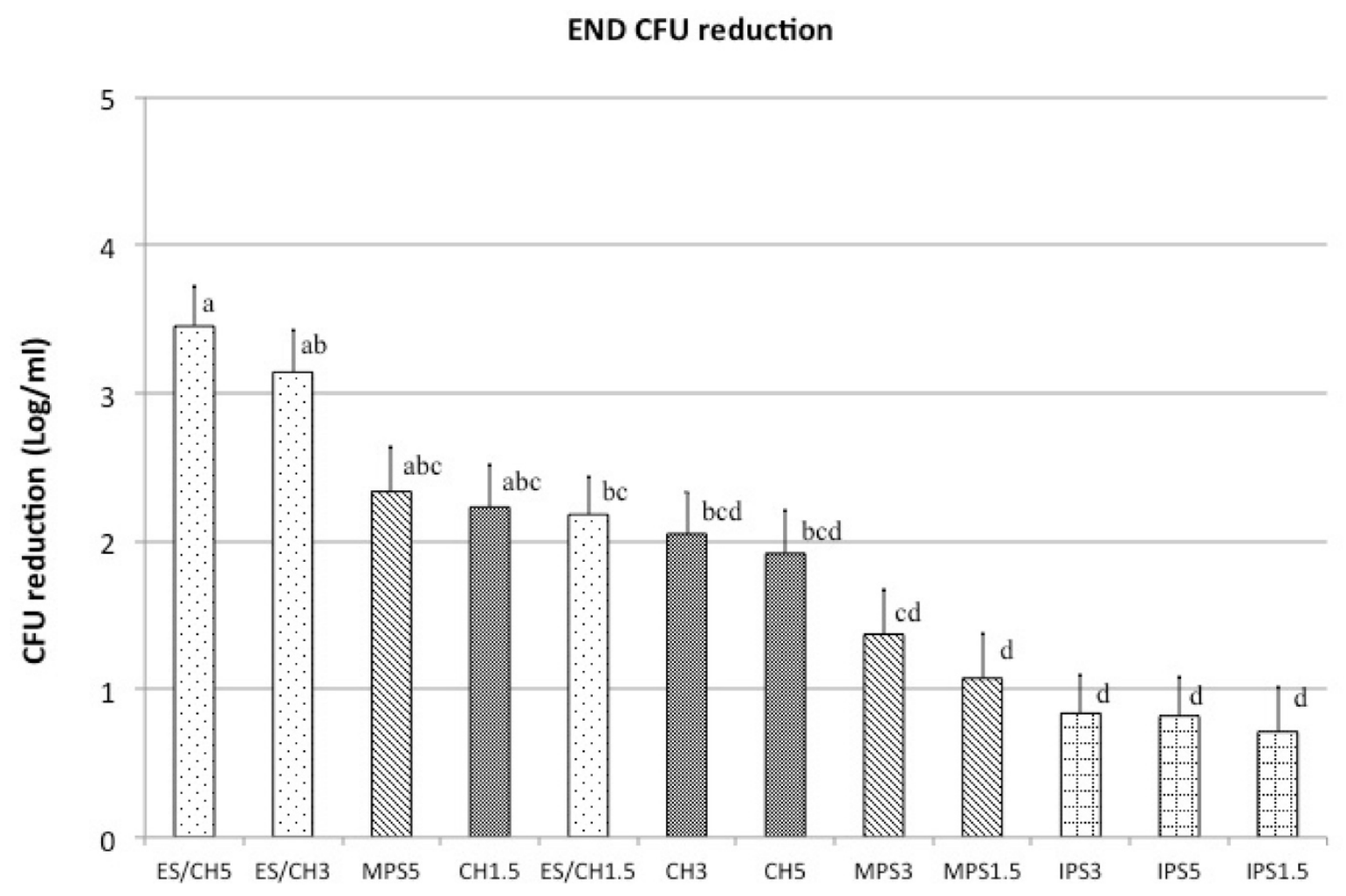

Study group

Figure 3 Mean $\log$ CFU reduction measured at the end of surgery (END) after using various hand preparation products.

Key: CH: 4\% Chlorhexidine gluconate scrub; MPS: 30\% 1-propanol and 45\% 2propanol solution; IPS: 70\% 2-propanol solution; ES/CH: 61\% ethanol solution with $1 \%$ chlorhexidine gluconate. Contact times: $1.5 \mathrm{~min}, 3 \mathrm{~min}, 5 \mathrm{~min}$. Values with different lowercase letters next to the column a, b, c, d are significantly different $(P<$ 0.05). Each error bar is constructed using 1 standard deviation from the mean. 


\subsection{Aerobic bacteria isolation}

We isolated 115 different species of bacteria from 34 different genera. The most commonly isolated gram-positive, gram-negative and spore-forming bacteria in the samples were Staphylococcus spp., Moraxella spp., and Bacillus spp., respectively.

The positive culture rates for gram-positive, gram-negative, coagulase-positive Staphylococcus spp. and spore-forming bacteria in each treatment group are shown in Table 3. For both POST and END samples, the positive culture rates for coagulasepositive Staphylococcus spp. and gram-negative bacteria were too low to allow for statistical analysis.

\subsubsection{Gram-positive aerobic bacteria}

For POST samples, the hand preparation product, but not contact time or PRE culture status, had a significant effect on positive culture rate $(P<0.001)$. Estimated positive culture rates for the four products were $\mathrm{ES} / \mathrm{CH}=11.9 \%, \mathrm{CH}=18.4 \%$, MPS $=70.6 \%$ and IPS=95.1\%. The ES/CH and $\mathrm{CH}$ groups each had a significantly lower positive culture rate than the MPS and IPS groups $(P<0.001)$. The MPS5 group had a significant lower positive culture rate than the IPS3 group $(P=0.003)$.

For END samples, both hand preparation product and PRE culture status had a significant effect on positive culture $(P<0.001$ and $P=0.009$, respectively). Estimated positive culture rates associated with the four products were $\mathrm{ES} / \mathrm{CH}=41.5 \%, \mathrm{CH}=75.7 \%$, IPS $=87.8 \%$ and MPS $=78.8 \%$. The ES/CH groups had a significantly lower positive culture rate than the CH, MPS and IPS groups $(P=0.002$, 
$P<0.001, P=0.001$, respectively). No significant differences were detected among the CH, MPS and IPS groups.

\subsubsection{Spore-forming aerobic bacteria}

For POST samples, the hand preparation product had a significant effect on positive culture results $(P<0.001)$. The predictive positive culture rates for aerobic spore-forming bacteria were $\mathrm{ES} / \mathrm{CH}=4.8 \%, \mathrm{CH}=15.8 \%$, IPS=90.2\% and $\mathrm{MPS}=73.5 \%$. The ES/CH and CH groups had significantly lower positive cultures than the MPS and IPS groups $(P<0.001)$. CH3 group had a significantly lower control rate to IPS $1.5(P=0.01)$, IPS $3(P=0.005)$, IPS $5(P=0.003)$, MPS $1.5(P=0.01)$ and MPS $3(P=$ $0.02)$.

For END samples, the hand preparation product did not have a significant effect on positive culture results. Surgery time had a significant positive association with culture status $(P=0.006)$, and contact time had a significant inverse association with culture status $(P=0.039)$. When surgery time was fixed at $150 \mathrm{~min}$, the predicted positive culture rates for aerobic spore-forming bacteria at various contact times were as follows: $1.5 \mathrm{~min}, 22.5 \%$; $3 \mathrm{~min}, 21.4 \%$; and $5 \mathrm{~min}, 6.4 \%$. A contact time of 5 min was associated with a significantly lower positive culture rate compared with $1.5 \min$ or $3 \min (P=0.022$ and 0.028 , respectively). The longer the surgery time (per hour), the more likely an aerobic spore-forming bacteria was isolated (odds ratio $=2.56,95 \% \mathrm{CI}=1.30-5.35$ ). 
Table 3 Positive culture rates associated with different surgical hand preparation methods

\begin{tabular}{|c|c|c|c|c|c|c|c|c|c|c|c|c|}
\hline \multirow{2}{*}{$\begin{array}{l}\text { Hand } \\
\text { Preparation } \\
\text { Method }\end{array}$} & \multicolumn{3}{|c|}{$\begin{array}{l}\text { Gram-positive bacteria (\%) } \\
95 \% \text { CI }\end{array}$} & \multicolumn{3}{|c|}{$\begin{array}{l}\text { Spore forming bacteria (\%) } \\
95 \% \text { CI }\end{array}$} & \multicolumn{3}{|c|}{$\begin{array}{l}\text { Coagulase-positive ST spp. } \\
95 \% \text { CI }\end{array}$} & \multicolumn{3}{|c|}{$\begin{array}{l}\text { Gram-negative bacteria (\%) } \\
95 \% \mathrm{CI}\end{array}$} \\
\hline & PRE & POST & END & PRE & POST & END & PRE & POST & END & PRE & POST & END \\
\hline ES/CH1.5 & $\begin{array}{l}100 \\
80-100\end{array}$ & $\begin{array}{l}20 \\
7-45^{*}\end{array}$ & $\begin{array}{l}73 \\
48-89 \dagger\end{array}$ & $\begin{array}{l}67 \\
42-85\end{array}$ & $\begin{array}{l}13 \\
4-38 \#\end{array}$ & $\begin{array}{l}7 \\
1-30\end{array}$ & $\begin{array}{l}0 \\
0-20\end{array}$ & $\begin{array}{l}0 \\
0-20\end{array}$ & $\begin{array}{l}0 \\
0-20\end{array}$ & $\begin{array}{l}40 \\
20-64\end{array}$ & $\begin{array}{l}0 \\
0-20\end{array}$ & $\begin{array}{l}0 \\
0-20\end{array}$ \\
\hline ES/CH3 & $\begin{array}{l}92 \\
67-98\end{array}$ & $\begin{array}{l}8 \\
1-33^{*}\end{array}$ & $\begin{array}{l}23 \\
8-50 \dagger\end{array}$ & $\begin{array}{l}62 \\
36-82\end{array}$ & $\begin{array}{l}0 \\
0-23 \#\end{array}$ & $\begin{array}{l}8 \\
1-33\end{array}$ & $\begin{array}{l}8 \\
1-33\end{array}$ & $\begin{array}{l}0 \\
0-23\end{array}$ & $\begin{array}{l}0 \\
0-23\end{array}$ & $\begin{array}{l}31 \\
13-58\end{array}$ & $\begin{array}{l}0 \\
0-23\end{array}$ & $\begin{array}{l}0 \\
0-23\end{array}$ \\
\hline ES/CH5 & $\begin{array}{l}100 \\
78-100\end{array}$ & $\begin{array}{l}7 \\
1-31 * \S\end{array}$ & $\begin{array}{l}21 \\
8-48 \dagger\end{array}$ & $\begin{array}{l}64 \\
39-84\end{array}$ & $\begin{array}{l}0 \\
0-22 \#\end{array}$ & $\begin{array}{l}0 \\
0-22\end{array}$ & $\begin{array}{l}7 \\
1-31\end{array}$ & $\begin{array}{l}0 \\
0-22\end{array}$ & $\begin{array}{l}0 \\
0-22\end{array}$ & $\begin{array}{l}7 \\
1-31\end{array}$ & $\begin{array}{l}0 \\
0-22\end{array}$ & $\begin{array}{l}0 \\
0-22\end{array}$ \\
\hline CH1.5 & $\begin{array}{l}100 \\
77-100\end{array}$ & $\begin{array}{l}23 \\
8-50^{*}\end{array}$ & $\begin{array}{l}69 \\
42-87\end{array}$ & $\begin{array}{l}46 \\
23-71\end{array}$ & $\begin{array}{l}15 \\
4-42 \#\end{array}$ & $\begin{array}{l}8 \\
1-33\end{array}$ & $\begin{array}{l}8 \\
1-33\end{array}$ & $\begin{array}{l}8 \\
1-33\end{array}$ & $\begin{array}{l}0 \\
0-23\end{array}$ & $\begin{array}{l}15 \\
4-42\end{array}$ & $\begin{array}{l}0 \\
0-23\end{array}$ & $\begin{array}{l}0 \\
0-23\end{array}$ \\
\hline $\mathrm{CH} 3$ & $\begin{array}{l}100 \\
77-100\end{array}$ & $\begin{array}{l}15 \\
4-42^{*}\end{array}$ & $\begin{array}{l}85 \\
58-96\end{array}$ & $\begin{array}{l}62 \\
36-82\end{array}$ & $\begin{array}{l}30 \\
13-58^{*}\end{array}$ & $\begin{array}{l}15 \\
4-42\end{array}$ & $\begin{array}{l}15 \\
4-42\end{array}$ & $\begin{array}{l}8 \\
1-33\end{array}$ & $\begin{array}{l}8 \\
1-33\end{array}$ & $\begin{array}{l}31 \\
13-58\end{array}$ & $\begin{array}{l}0 \\
0-23\end{array}$ & $\begin{array}{l}0 \\
0-23\end{array}$ \\
\hline CH5 & $\begin{array}{l}92 \\
65-99\end{array}$ & $\begin{array}{l}17 \\
5-45^{*}\end{array}$ & $\begin{array}{l}67 \\
39-86\end{array}$ & $\begin{array}{l}50 \\
25-75\end{array}$ & $\begin{array}{l}0 \\
0-24 \#\end{array}$ & $\begin{array}{l}17 \\
5-45\end{array}$ & $\begin{array}{l}25 \\
9-53\end{array}$ & $\begin{array}{l}8 \\
1-35\end{array}$ & $\begin{array}{l}8 \\
1-35\end{array}$ & $\begin{array}{l}25 \\
9-53\end{array}$ & $\begin{array}{l}0 \\
0-24\end{array}$ & $\begin{array}{l}8 \\
1-35\end{array}$ \\
\hline IPS1.5 & $\begin{array}{l}100 \\
74-100\end{array}$ & $\begin{array}{l}100 \\
74-100\end{array}$ & $\begin{array}{l}90 \\
62-98\end{array}$ & $\begin{array}{l}55 \\
28-79\end{array}$ & $\begin{array}{l}91 \\
62-98\end{array}$ & $\begin{array}{l}27 \\
10-57\end{array}$ & $\begin{array}{l}0 \\
0-26\end{array}$ & $\begin{array}{l}0 \\
0-26\end{array}$ & $\begin{array}{l}9 \\
2-38\end{array}$ & $\begin{array}{l}27 \\
10-57\end{array}$ & $\begin{array}{l}0 \\
0-26\end{array}$ & $\begin{array}{l}0 \\
0-26\end{array}$ \\
\hline IPS3 & $\begin{array}{l}100 \\
79-100\end{array}$ & $\begin{array}{l}87 \\
62-96\end{array}$ & $\begin{array}{l}80 \\
55-93\end{array}$ & $\begin{array}{l}60 \\
36-80\end{array}$ & $\begin{array}{l}87 \\
62-96\end{array}$ & $\begin{array}{l}33 \\
15-58\end{array}$ & $\begin{array}{l}7 \\
1-30\end{array}$ & $\begin{array}{l}0 \\
0-20\end{array}$ & $\begin{array}{l}7 \\
1-30\end{array}$ & $\begin{array}{l}13 \\
4-38\end{array}$ & $\begin{array}{l}0 \\
0-20\end{array}$ & $\begin{array}{l}0 \\
0-20\end{array}$ \\
\hline
\end{tabular}




\begin{tabular}{|c|c|c|c|c|c|c|c|c|c|c|c|c|}
\hline IPS5 & $\begin{array}{l}100 \\
80-100\end{array}$ & $\begin{array}{l}100 \\
80-100\end{array}$ & $\begin{array}{l}93 \\
70-99\end{array}$ & $\begin{array}{l}60 \\
36-80\end{array}$ & $\begin{array}{l}93 \\
70-99\end{array}$ & $\begin{array}{l}7 \\
1-30\end{array}$ & $\begin{array}{l}20 \\
7-45\end{array}$ & $\begin{array}{l}0 \\
0-20\end{array}$ & $\begin{array}{l}7 \\
1-30\end{array}$ & $\begin{array}{l}27 \\
11-52\end{array}$ & $\begin{array}{l}0 \\
0-20\end{array}$ & $\begin{array}{l}0 \\
0-20\end{array}$ \\
\hline MPS1.5 & $\begin{array}{l}100 \\
76-100\end{array}$ & $\begin{array}{l}83 \\
55-95\end{array}$ & $\begin{array}{l}67 \\
40-86\end{array}$ & $\begin{array}{l}67 \\
39-86\end{array}$ & $\begin{array}{l}75 \\
47-91\end{array}$ & $\begin{array}{l}42 \\
19-68\end{array}$ & $\begin{array}{l}42 \\
19-68\end{array}$ & $\begin{array}{l}17 \\
5-45\end{array}$ & $\begin{array}{l}0 \\
0-24\end{array}$ & $\begin{array}{l}33 \\
14-61\end{array}$ & $\begin{array}{l}33 \\
14-61\end{array}$ & $\begin{array}{l}0 \\
0-24\end{array}$ \\
\hline MPS3 & $\begin{array}{l}100 \\
74-100\end{array}$ & $\begin{array}{l}82 \\
52-95\end{array}$ & $\begin{array}{l}91 \\
62-98\end{array}$ & $\begin{array}{l}55 \\
28-79\end{array}$ & $\begin{array}{l}82 \\
52-95\end{array}$ & $\begin{array}{l}18 \\
5-48\end{array}$ & $\begin{array}{l}27 \\
10-57\end{array}$ & $\begin{array}{l}0 \\
0-26\end{array}$ & $\begin{array}{l}0 \\
0-26\end{array}$ & $\begin{array}{l}9 \\
2-38\end{array}$ & $\begin{array}{l}0 \\
0-26\end{array}$ & $\begin{array}{l}0 \\
0-26\end{array}$ \\
\hline MPS5 & $\begin{array}{l}91 \\
62-98\end{array}$ & $\begin{array}{l}45 \\
21-72 \ddagger\end{array}$ & $\begin{array}{l}72 \\
43-90\end{array}$ & $\begin{array}{l}55 \\
28-79\end{array}$ & $\begin{array}{l}64 \\
35-85\end{array}$ & $\begin{array}{l}9 \\
2-38\end{array}$ & $\begin{array}{l}9 \\
2-38\end{array}$ & $\begin{array}{l}0 \\
0-26\end{array}$ & $\begin{array}{l}0 \\
0-26\end{array}$ & $\begin{array}{l}0 \\
0-26\end{array}$ & $\begin{array}{l}0 \\
0-26\end{array}$ & $\begin{array}{l}0 \\
0-26\end{array}$ \\
\hline
\end{tabular}

CH, 4\% Chlorhexidine gluconate scrub; MPS, 30\% 1-propanol and 45\% 2-propanol solution; IPS, 70\% 2-propanol solution; ES/CH, 61\% ethanol solution with $1 \%$ chlorhexidine gluconate. ST, Staphylococcus. PRE, before surgical hand preparation; POST, after surgical hand preparation; END, at the end of surgery.

* Significantly lower culture rates compared with IPS, MPS1.5 and MPS3 $(P<0.05)$

$\S$ Significantly lower culture rate compare with MPS5 $(P<0.05)$

\# Significantly lower culture rates compared with IPS3 $(P<0.05)$

† Significantly lower culture rates compared with CH, MPS and IPS $(P<0.05)$

\# Significantly lower culture rates compared with both IPS and MPS $(P<0.05)$ 
5 DISCUSSION 


\subsection{Antibacterial efficacy of the tested products}

In this study, at manufacturer-recommended contact times, $\mathrm{ES} / \mathrm{CH}$ and $\mathrm{CH}$ provided significantly greater bacterial reduction compared with MPS and IPS, immediately after surgical hand preparation. By the end of surgery, ES/CH again showed significantly stronger bacterial reduction compared with IPS. These results may be attributed to several factors. First, although the participants were instructed in proper hand-rubbing techniques before application, and they were observed during the application process, as students they might not yet be familiar with the technique. Compared with ES/CH, products containing IPS and MPS evaporate rapidly and it is possible that contact areas were missed during application.

One study showed that when ABR products were used with an active ingredient similar to IPS for hand sanitization, additional training improved the bacterial reduction and decreased the area of missed contact. ${ }^{156}$ Another study showed that a significant difference in the outcome of antibacterial efficacy existed between medical students in the first two academic years versus students in the final two years. ${ }^{108}$ In our study, the participants were third-year veterinary students who had no prior experience in surgical hand preparation; therefore they might not have applied the products correctly. The question of whether ES/CH can help to decrease missing contact spots, and whether additional training would help to improve the efficacy of ABRs for surgical hand preparation, require further investigation.

Second, moisture retained on the hands after washing and drying may impair the efficacy of ABR by decreasing the alcohol concentration on the skin, therefore 
impair the efficacy of IPS and MPS. The bacteriostatic and bacteriocidal concentrations for chlorhexidine gluconate have been reported to be as low as 1 $\mathrm{mcg} / \mathrm{ml}$ and $20 \mathrm{mcg} / \mathrm{ml}$, respectively. ${ }^{12}$ Although retained moisture may also diluted $\mathrm{CH}$ and $\mathrm{CH} / \mathrm{ES}$, even with dilution, the concentration of chlorhexidine gluconate on the hands may still be above $1 \mathrm{mcg} / \mathrm{ml}$ and residual antibacterial activity would persist. In human medicine, the debate on whether hand-washing prior to ABR application is necessary has not yet been settled.7,154 However, because of the nature of veterinary medicine, washing hands prior to ABR application is still considered desirable.

Third, glycerol is commonly used in hand-care products, and this substance might have altered the efficacy of IPS and MPS, as it has been shown to decrease the efficacy of pure alcohol hand rubs. ${ }^{157}$ All participants were instructed to wash their hands with a neutral soap for at least 1 min or until their hands were free of organic matter. The use of hand-care products by the students was not prohibited during the study. Unfortunately, glycerol within hand-care products can be hard to remove by a single hand wash. ${ }^{153}$

\subsection{The effects of increased contact time on bacterial reduction}

A previous study reported no difference in bacterial reduction between 1.5-min and 3-min application times of MPS among healthy volunteers. ${ }^{14} \mathrm{~A}$ contact time of up to 5 min with $A B R$ had not been evaluated to date, especially because one of the claimed benefits of ABR is a shorter application time. In our study, an increase in contact time did not help to improve bacteria reduction immediately after surgical 
hand preparation; however, it did significantly improve the bacterial reduction associated with ES/CH and MPS by the end of surgery. An increased amount of product would be necessary to achieve longer contact times, and the repeated rubbing process might have helped to decrease the missed spots and to improve the antibacterial efficacy. ${ }^{156}$ Nonetheless, this additional bacterial reduction was only observed at the end of surgery. The evaluation of possible clinical benefits requires further research. Although ABR is regarded as a relatively safe product, potential disadvantages to the use of large amounts could include dermal and respiratory absorption of alcohol, irritation to the respiratory tract, and possible fire hazard. ${ }^{115,151,158,159}$

\subsection{Selective bacterial inhibition of pure alcohol based rubs}

A total of 115 species among 34 different genera of bacteria were identified using MALDI-TOF. It was not the purpose of this study to evaluate skin flora on veterinary students, therefore selective culture, phenotype and genotype identification were not performed. It would be interesting to conduct further research to determine the prevalence of multidrug-resistant bacteria colonization among veterinary personnel. However, our study was limited to determining whether antibacterial efficacy differs according to the surgical hand preparation method.

The recovery rate of spore-forming bacteria - such as Bacillus spp. and Paenibacillus spp. - increased after MPS and IPS application, at all three contact times in the POST samples. Alcohol displays no sporicidal activity and ethanol has 
even been used for selective isolation of spore-forming bacteria. ${ }^{12,88} 161$ We suspect that our observation might be the result of a similar selective culture process, as such differences were not observed in the END samples. It is possible the sporeforming bacteria were present, but were not detected as commonly in the END samples as in the POST samples, due to an overall increase in bacterial colonies on the agar plate. To our knowledge, this is the first study that demonstrates a difference in culture rate for spore-forming bacteria after surgical hand preparation using pure alcohol rubs (MPS and IPS). The spore-forming bacteria isolated in our study were of low virulence and are rarely cultured from infected wounds. Nonetheless, this finding should be considered when choosing surgical hand rubs for immune-compromised patients, or for surgeries in which infection would be catastrophic - such as internal fixation or joint replacement.

\subsection{Surgical site infection rate}

Due to the small case number, we did not expect to see any significant difference in surgical site infection rate that would allow meaningful statistical analysis. Only one SSI occurred during the study period. Interestingly, Staphylococcus pseudintermedius was isolated from the infected incision. In this case, Staphylococcus pseudintermedius was not cultured from either the surgeon or the assistant, suggesting that the infection may occur from a source other than residual hand bacteria. The exact relationship between bacterial burden on a surgeon's hands and the surgical infection rate remains unknown. Several human studies have shown that in modern surgery environments, the SSI rate did not differ significantly when ABRs were used, compared with the results for plain soap hand-washing and 
CH scrubbing. ${ }^{133,134,137}$ Another study showed that glove perforation was associated with a significant increase in infection rate if no antimicrobial prophylaxis was administered.133 These studies highlight the concept that SSI is a multi-factorial complication. Surgery type, surgeon and patient preparation, operating room behavior and tissue trauma are all important variables for SSI. ${ }^{17}$ Similar research is lacking in veterinary medicine and would require a large-scale multi-institutional study. Nonetheless, such work is needed to help elucidate the clinical benefit to veterinary patients of different surgical hand antisepsis protocols.

\subsection{Limitations}

Several limitations in this study are noted. First, the participants and authors were not blinded to specific products used, or contact time. Second, only sheepblood agar plates were used for the culturing. The use of MacConkey agar plates would have allowed for the identification of a greater spectrum of gram-negative bacteria. Third, the average duration of surgery in our study was relatively short, and no cumulative effects were tested. Thus, our data should be interpreted with caution for operations of longer duration and for clinical settings in which repeated surgical hand preparations are performed throughout a single day. Lastly, neutralizing agents for $\mathrm{CH}$ were not added to any of the samples. Controversy persists as to whether residual neutralizing agents on the skin can reduce the effectiveness of surgical hand preparation, or whether the antimicrobial activity of non-volatile $\mathrm{CH}$ would improve due to a residue effect. ${ }^{141}$ 
Different neutralizers, of unknown efficacies, used in various studies further complicate any comparison with our results. At the time of this study, the US FDA had not provided clear guidelines on whether neutralizing agents should be used in studies evaluation surgical hand preparation protocols, but has recommended that all research reports should clearly state the neutralization status to facilitate the comparison of results across studies. ${ }^{121}$ Considering that historically studies in veterinary medicine have been performed without the use of neutralizer, ${ }^{143,162,163}$ we chose not to use a neutralizer in our research. Additionally, neutralization agents have been shown to be most effective when added directly to the sampling fluid. ${ }^{141}$ Considering our study design, a neutralization agent could potential negate any residual effect of an antiseptic agent and might increase the risk of post-surgical complications since no additional hand preparation was performed between the first sample collection (after preparation) and second sampling (by the end of surgery).

\subsection{New FDA standards for testing surgical hand antisepsis}

After the commencement of this study and manuscript submission, the FDA published a new standard for testing surgical hand antisepsis. ${ }^{164}$ The recommendation is that an appropriate neutralizer should be used in all recovery media (sampling solution, dilution fluid and plate media), and validation of such neutralizers is recommended. The manner in which this recommendation might lead to new conclusions based on studies performed previously would require further study. 
The new FDA standards also proposes new criteria for bacterial log reduction in testing the effectiveness of surgical hand antisepsis products. The criteria are that a reduction of at least $2 \log _{10}$ on each hand within 1 min is required, and such reduction should not exceed baseline at $6 \mathrm{~h} \cdot{ }^{164}$ Using this standard, all IPS groups in our study would be rated ineffective because their log reduction was less than 2 units immediately after application (Figure 2, Figure 3). 
6 CONCLUSION AND FUTURE DIRECTIONS 
Optimal surgical hand preparation solutions should be effective at removing transient bacteria and reducing bacterial regrowth. They should also cause minimal skin irritation and generate the least amount of waste. In this study, using both alcohol-based and non-alcohol based solutions effectively reduced bacterial counts at all product/time combinations. However, the findings indicate that pure alcohol products, such as MPS and IPS, were not as effective as $\mathrm{CH}$ products when used by veterinary students. Alcohol products achieved lower logCFU bacterial reductions as measured after surgical hand preparation and at the end of surgery, and were associated with higher observed positive culture rates, compared with products containing chlorhexidine gluconate. Increase in contact time failed to improve the immediate antibacterial efficacy in both alcohol and $\mathrm{CH}$ based solution. The results of our study suggest veterinary students should use $\mathrm{CH}$ hand scrub or ES/CH rubs for surgical hand preparation. These results may also prove pertinent for other veterinary surgeons; however, further research is needed on the various surgical hand preparation products and procedures among other groups. A larger body of empirical knowledge would enable meaningful comparisons and recommendations to be derived. 


\section{REFERENCES}

1. Kirkland KB, Briggs JP, Trivette SL, Wilkinson WE, Sexton DJ. The impact of surgical-site infections in the 1990s: attributable mortality, excess length of hospitalization, and extra costs. Infec Control Hosp Epidemiol. 1999 Nov;20:725-730.

2. Nicoll C, Singh A, Weese JS. Economic impact of tibial plateau leveling osteotomy surgical site infection in dogs. Vet Surg. 2014 Nov;43:899-902.

3. Hayes GM, Reynolds D, Moens NMM, et al. Investigation of incidence and risk factors for surgical glove perforation in small animal surgery. Vet Surg. 2014 May;43:400-404.

4. Biermann NM, Doyle AJ, Sanchez J. Observational study on the occurrence of surgical glove perforation and associated risk factors in large animal surgery. Proceedings ACVS symposium. 2015.

5. Tanner J, Swarbrook S, Stuart J. Surgical hand antisepsis to reduce surgical site infection. Tanner J (ed): Cochrane Database Syst Rev. 2008 Jan 23;:CD004288.

6. Lister J. On the antiseptic principle in the practice of surgery. The Lancet. 1867 Sep;90:353-356.

7. World Health Organization. WHO Guidelines on Hand Hygiene in Health Care. World Health Organization; 2009.

8. Rocha LA, Ferreira de Almeida e Borges L, Gontijo Filho PP. Changes in hands microbiota associated with skin damage because of hand hygiene procedures on the health care workers. Am J Infect Control. 2009 Mar;37:155-159.

9. Widmer AF. Surgical hand hygiene: scrub or rub? J Hosp Infect. 2013 Feb;83 Suppl 1:S35-S39.

10. Anderson MEC, Foster BA, Weese JS. Observational study of patient and surgeon preoperative preparation in ten companion animal clinics in Ontario, Canada. BMC Vet Res. 2013 Oct 5;9:194.

11. Cimiotti JP, Stone PW, Larson EL. A cost comparison of hand hygiene regimens. Nurs Econ. 2004 Jul;22:196-199.

12. Kampf G, Kramer A. Epidemiologic background of hand hygiene and evaluation of the most important agents for scrubs and rubs. Clin Microbiol Rev. 2004 Oct;17:863-893. 
13. Suchomel M, Rotter M, Weinlich M, Kundi M. Glycerol significantly decreases the three hour efficacy of alcohol-based surgical hand rubs. J Hosp Infect. 2013 Apr;83:284-287.

14. Kampf G, Ostermeyer C, Heeg P. Surgical hand disinfection with a propanolbased hand rub: equivalence of shorter application times. J Hosp Infect. 2005 Apr;59:304-310.

15. Verwilghen D, Grulke S, Kampf G. Presurgical hand antisepsis: concepts and current habits of veterinary surgeons. Vet Surg. 2011 Jul;40:515-521.

16. McHugh SM, Corrigan MA, Hill ADK, Humphreys H. Surgical attire, practices and their perception in the prevention of surgical site infection. Surgeon. 2014 Feb;12:47-52.

17. Nelson LL. Surgical site infections in small animal surgery. Vet Clin North Am Sm Anim Pract. 2011 Sep;41:1041-56.

18. Tammelin A, Hambræus A, Ståhle E. Routes and sources of Staphylococcus aureus transmitted to the surgical wound during cardiothoracic surgery: possibility of preventing wound contamination by use of special scrub suits. Infec Control Hosp Epidemiol. 2001 Jun;22:338-346.

19. Ritter MA, Eitzen H, French ML, Hart JB. The operating room environment as affected by people and the surgical face mask. Clin Orthop Relat Res. 1975 Sep;:147-150.

20. Tobias KM, Johnston SA. Veterinary Surgery: Small Animal. Veterinary Surgery Small Animal. $1^{\text {st }}$ edi. Elsevier Health Sciences; 2013

21. Brown DC, Conzemius MG, Shofer F, Swann H. Epidemiologic evaluation of postoperative wound infections in dogs and cats. J Am Vet Med Assoc. 1997 May 1;210:1302-1306.

22. Mayhew PD, Freeman L, Kwan T, Brown DC. Comparison of surgical site infection rates in clean and clean-contaminated wounds in dogs and cats after minimally invasive versus open surgery: 179 cases (2007-2008). J Am Vet Med Assoc. 2012 Jan 15;240:193-198.

23. Beal MW, Brown DC, Shofer FS. The effects of perioperative hypothermia and the duration of anesthesia on postoperative wound infection rate in clean wounds: a retrospective study. Vet Surg. 2000 Mar;29:123-127.

24. Weese JS. A review of post-operative infections in veterinary orthopaedic surgery. Vet Comp Orthop Traumatol. 2008;21:99-105.

25. Fitzpatrick N, Solano MA. Predictive variables for complications after TPLO 
with stifle inspection by arthrotomy in 1000 consecutive dogs. Vet Surg. 2010 Jun;39:460-474.

26. MacDonald DG, Morley PS, Bailey JV, Barber SM, Fretz PB. An examination of the occurrence of surgical wound infection following equine orthopaedic surgery (1981-1990). Equine Vet J. 1994 Jul;26:323-326.

27. Ahern BJ, Richardson DW, Boston RC, Schaer TP. Orthopedic infections in equine long bone fractures and arthrodeses treated by internal fixation: 192 cases (1990-2006). Vet Surg. 2010 Jul;39:588-593.

28. Isgren CM, Salem SE, Archer DC, Worsman FCF, Townsend NB. Risk factors for surgical site infection following laparotomy: Effect of season and perioperative variables and reporting of bacterial isolates in 287 horses. Equine Vet J. 2017 Jan 1;49:39-44.

29. Reichman DE, Greenberg JA. Reducing surgical site infections: a review. Rev Obstet Gynecol. 2009;2:212-221.

30. Astagneau P, Rioux C, Golliot F, Brücker G, INCISO Network Study Group. Morbidity and mortality associated with surgical site infections: results from the 1997-1999 INCISO surveillance. J Hosp Infect. 2001 Aug;48:267-274.

31. McLure HA, Talboys CA, Yentis SM, Azadian BS. Surgical face masks and downward dispersal of bacteria. Anaesthesia. 1998 Jul 1;53:624-626.

32. AORN Recommended Practices Committee. Recommended practices for surgical attire. AORN J. 2005;413-420.

33. Broex ECJ, van Asselt ADI, Bruggeman CA, van Tiel FH. Surgical site infections: how high are the costs? J Hosp Infect. 2009 Jul;72:193-201.

34. de Lissovoy G, Fraeman K, Hutchins V, Murphy D, Song D, Vaughn BB. Surgical site infection: incidence and impact on hospital utilization and treatment costs. Am J Infect Control. 2009 Jun;37:387-397.

35. Mangram AJ, Horan TC, Pearson ML, Silver LC, Jarvis WR. Guideline for Prevention of Surgical Site Infection, 1999. Centers for Disease Control and Prevention (CDC) Hospital Infection Control Practices Advisory Committee. Am J Infect Control. 1999;97-132.

36. Heldmann E, Brown DC, Shofer F. The association of propofol usage with postoperative wound infection rate in clean wounds: a retrospective study. Vet Surg. 1999 Jul;28:256-259.

37. Vasseur PB, Levy J, Dowd E, Eliot J. Surgical wound infection rates in dogs and cats. Data from a teaching hospital. Vet Surg. 1988 Mar;17:60-64. 
38. Gallagher AD, Mertens WD. Implant removal rate from infection after tibial plateau leveling osteotomy in dogs. Vet Surg. 2012 Aug;41:705-711.

39. Savicky R, Beale B, Murtaugh R, Swiderski-Hazlett J, Unis M. Outcome following removal of TPLO implants with surgical site infection. Vet Comp Orthop Traumatol. 2013;26:260-265.

40. Eugster S, Schawalder P, Gaschen F, Boerlin P. A prospective study of postoperative surgical site infections in dogs and cats. Vet Surg. 2004 Sep;33:542-550.

41. Nicholson M, Beal M, Shofer F, Brown DC. Epidemiologic evaluation of postoperative wound infection in clean-contaminated wounds: A retrospective study of 239 dogs and cats. Vet Surg. 2002 Nov;31:577-581.

42. Olmstead ML, Hohn RB, Turner TM. A five-year study of 221 total hip replacements in the dog. J Am Vet Med Assoc. 1983 Jul 15;183:191-194.

43. Paul HA, Bargar WL. A modified technique for canine total hip replacement. J Am Anim Hosp Assoc. J Am Anim Hosp Assoc. 1987 23:1:13-18

44. Bergh MS, Gilley RS, Shofer FS, Kapatkin AS. Complications and radiographic findings following cemented total hip replacement: a retrospective evaluation of 97 dogs. Vet Comp Orthop Traumatol. 2006;19:172-179.

45. Nazarali A, Singh A, Weese JS. Perioperative administration of antimicrobials during tibial plateau leveling osteotomy. Vet Surg. 2014 Nov;43:966-971.

46. Solano MA, Danielski A, Kovach K, Fitzpatrick N, Farrell M. Locking plate and screw fixation after tibial plateau leveling osteotomy reduces postoperative infection rate in dogs over 50 kg. Vet Surg. 2015 Jan;44:59-64.

47. Etter SW, Ragetly GR, Bennett RA, Schaeffer DJ. Effect of using triclosanimpregnated suture for incisional closure on surgical site infection and inflammation following tibial plateau leveling osteotomy in dogs. J Am Vet Med Assoc. 2013 Feb 1;242:355-358.

48. Gatineau M, Dupuis J, Plante J, Moreau M. Retrospective study of 476 tibial plateau levelling osteotomy procedures. Rate of subsequent "pivot shift," meniscal tear and other complications. Vet Comp Orthop Traumatol. 2011;24:333-341.

49. Frey TN, Hoelzler MG, Scavelli TD, Fulcher RP, Bastian RP. Risk factors for surgical site infection-inflammation in dogs undergoing surgery for rupture of the cranial cruciate ligament: 902 cases (2005-2006). J Am Vet Med Assoc. 2010 Jan 1;236:88-94. 
50. Lafaver S, Miller NA, Stubbs WP, Taylor RA, Boudrieau RJ. Tibial tuberosity advancement for stabilization of the canine cranial cruciate ligamentdeficient stifle joint: surgical technique, early results, and complications in 101 dogs. Vet Surg. 2007 Aug;36:573-586.

51. McIlwraith CW, Yovich JV, Martin GS. Arthroscopic surgery for the treatment of osteochondral chip fractures in the equine carpus. J Am Vet Med Assoc. 1987 Sep 1;191:531-540.

52. Humphreys H, Russell AJ, Marshall RJ, Ricketts VE, Reeves DS. The effect of surgical theatre head-gear on air bacterial counts. J Hosp Infect. 1991 Nov;19:175-180.

53. Salassa TE, Swiontkowski MF. Surgical attire and the operating room: role in infection prevention. J Bone Joint Surg Am. 2014 Sep 3;96:1485-1492.

54. Eisen DB. Surgeon's garb and infection control: what's the evidence? J Am Acad Dermatol. 2011 May;64:960.e1-e20.

55. Nazarali A, Singh A, Moens NMM, et al. Association between methicillinresistant Staphylococcus pseudintermedius carriage and the development of surgical site infections following tibial plateau leveling osteotomy in dogs. J Am Vet Med Assoc. 2015 Oct 15;247:909-916.

56. Kalra L, Camacho F, Whitener CJ, et al. Risk of methicillin-resistant Staphylococcus aureus surgical site infection in patients with nasal MRSA colonization. Am J Infect Control. 2013 Dec;41:1253-1257.

57. Gupta K, Strymish J, Abi-Haidar Y, Williams SA, Itani KMF. Preoperative nasal methicillin-resistant Staphylococcus aureus status, surgical prophylaxis, and risk-adjusted postoperative outcomes in veterans. Infec Control Hosp Epidemiol. 2011 Aug;32:791-796.

58. Yano K, Minoda Y, Sakawa A, et al. Positive nasal culture of methicillinresistant Staphylococcus aureus (MRSA) is a risk factor for surgical site infection in orthopedics. Acta Orthopaedica. 2009 Aug;80:486-490.

59. Misteli H, Weber WP, Reck S, et al. Surgical glove perforation and the risk of surgical site infection. Arch Surg. 2009 Jun;144:553-8-discussion558.

60. Neely AN, Maley MP. Survival of enterococci and staphylococci on hospital fabrics and plastic. J Clin Microbiol. 2000 Feb;38:724-726.

61. Lowbury E. Airborne contamination of wounds in joint replacement operations: the relationship to sepsis rates. J Hosp Infect. 1983;4:111-131.

62. Whyte W, Hodgson R, Tinkler J. The importance of airborne bacterial 
contamination of wounds. J Hosp Infect. Elsevier; 1982;3:123-135.

63. Milstone AM, Passaretti CL, Perl TM. Chlorhexidine: expanding the armamentarium for infection control and prevention. Clin Infect Dis. 2008 Jan 15;46:274-281.

64. Price PB. The bacteriology of normal skin; a new quantitative test applied to a study of the bacterial flora and the disinfectant action of mechanical cleansing. J infect Dis diseases. 1938:301-318.

65. Lowbury EJ, Lilly HA, Ayliffe GA. Preoperative disinfection of surgeons' hands: use of alcoholic solutions and effects of gloves on skin flora. Br Med J. 1974 Nov 16;4:369-372.

66. Larson EL, 1994 APIC Guidelines Committee. APIC guidelines for handwashing and hand antisepsis in health care settings. Am J Infect Control. 1995;23:251-269.

67. Rayan GM, Flournoy DJ. Microbiologic flora of human fingernails. J Hand Surg Am. 1987 Jul;12:605-607.

68. Mulberrry G, Snyder AT, Heilman J, Pyrek J, Stahl J. Evaluation of a waterless, scrubless chlorhexidine gluconate/ethanol surgical scrub for antimicrobial efficacy. Am J Infect Control. 2001 Dec;29:377-382.

69. Larson EL, Aiello AE, Heilman JM, et al. Comparison of different regimens for surgical hand preparation. AORN J. 2001 Feb;73:412-418

70. Rotter ML. Hand washing and hand disinfection. Rotter M. Hand washing and hand disinfection. Hospital epidemiology and infection control. 2nd ed. Philadelphia, PA: Lippincott Williams \& Wilkins; 1999

71. Rotter ML. Arguments for alcoholic hand disinfection. J Hosp Infect. 2001;48:S4-S8.

72. Daschner FD. The transmission of infections in hospitals by staff carriers, methods of prevention and control. Infect Control. 1985 Mar;6:97-99.

73. Blanc DS, Nahimana I, Petignat C, Wenger A, Bille J, Francioli P. Faucets as a reservoir of endemic Pseudomonas aeruginosa colonization/infections in intensive care units. Intensive Care Med. 2004 Oct;30:1964-1968.

74. Van Der Zwet WC, Parlevliet GA, Savelkoul PH, et al. Outbreak of Bacillus cereus infections in a neonatal intensive care unit traced to balloons used in manual ventilation. J Clin Microbiol. 2000 Nov;38:4131-4136.

75. Wang J-L, Chen M-L, Lin YE, Chang S-C, Chen Y-C. Association between 
contaminated faucets and colonization or infection by nonfermenting gramnegative bacteria in intensive care units in Taiwan. J Clin Microbiol. American Society for Microbiology; 2009 0ct;47:3226-3230.

76. Best M, Neuhauser D. Ignaz Semmelweis and the birth of infection control. Qual Saf Health Care. 2004 Jun 1;13:233-234.

77. Dharan S, Pittet D. Environmental controls in operating theatres. J Hosp Infect. 2002 51:79-84

78. Spencer M, Edmiston CE. The role of the OR environment in preventing surgical site infections. AORN J. 2014 Dec;100:603-608.

79. Waddington $\mathrm{C}$. Changing behavior: evidence based practice supporting hair removal with clippers. ORL Head Neck Nurs. 2008;26:8-12.

80. Mangram AJ, Horan TC, Pearson ML, Silver LC, Jarvis WR. Guideline for prevention of surgical site infection, 1999. Hospital Infection Control Practices Advisory Committee. Infec Control Hosp Epidemiol. 1999;250-78quiz279-80.

81. Tanner J, Norrie P, Melen K. Preoperative hair removal to reduce surgical site infection. Tanner J (ed): Cochrane Database Syst Rev. 2011 Nov 9;:CD004122.

82. Balthazar ER, Colt JD, Nichols RL. Preoperative hair removal: a random prospective study of shaving versus clipping. South Med J. 1982 Jul;75:799801.

83. Powell H, Swarner O, Gluck L, Lampert P. Hexachlorophene myelinopathy in premature infants. J Pediatr. 1973 Jun;82:976-981.

84. Bartzokas CA, Gibson MF, Graham R, Pinder DC. A comparison of triclosan and chlorhexidine preparations with 60 per cent isopropyl alcohol for hygienic hand disinfection. J Hosp Infect. 1983 Sep;4:245-255.

85. McDonnell G, Russell AD. Antiseptics and disinfectants: activity, action, and resistance. Clin Microbiol Rev. 1999 Jan;12:147-179.

86. Webster J, Croger S, Lister C, Doidge M, Terry MJ, Jones I. Use of face masks by non-scrubbed operating room staff: a randomized controlled trial. ANZ J Surg. Blackwell Publishing Asia; 2010 Mar;80:169-173.

87. Tunevall TG. Postoperative wound infections and surgical face masks: a controlled study. World J Surg. 1991 May;15:383-388.

88. Russell AD. Bacterial spores and chemical sporicidal agents. Clin Microbiol 
Rev. 1990 Apr 1;3:99-119.

89. Joress SM. A Study of Disinfection of the Skin: A Comparison of PovidoneIodine with Other Agents used for Surgical Scrubs. Annals of Surgery. 1962 Feb 1;155:296-304.

90. McLure AR, Gordon J. In-vitro evaluation of povidone-iodine and chlorhexidine against methicillin-resistant Staphylococcus aureus. J Hosp Infect. 1992 Aug;21:291-299.

91. Summers MM, LYNCH PF, BLACK T. Hair as a reservoir of staphylococci. J Clin Pathol. 1965 Jan 1;18:13-15.

92. Nicolay CR. Hand hygiene: an evidence-based review for surgeons. Int J Surg. 2006;4:53-65.

93. Mastro TD, Farley TA, Elliott JA, et al. An outbreak of surgical-wound infections due to group A streptococcus carried on the scalp. N Engl J Med. 1990 Oct 4;323:968-972.

94. Vali L, Davies SE, Lai LLG, Dave J, Amyes SGB. Frequency of biocide resistance genes, antibiotic resistance and the effect of chlorhexidine exposure on clinical methicillin-resistant Staphylococcus aureus isolates. J Antimicrob Chemother. 2008 Mar;61:524-532.

95. Pethica BA. Lysis by physical and chemical methods. J Gen Microbiol. 1958 Apr;18:473-480.

96. Lister J. Antiseptic principle in the practice of surgery. BMJ. 1967;2:9-12.

97. Furukawa K, Tajiri T, Suzuki H, Norose Y. Are sterile water and brushes necessary for hand washing before surgery in Japan? J Nippon Med Sch. 2005 Jun;72:149-154.

98. McNeil SA, Foster CL, Hedderwick SA, Kauffman CA. Effect of hand cleansing with antimicrobial soap or alcohol-based gel on microbial colonization of artificial fingernails worn by health care workers. Clin Infect Dis. $2001 \mathrm{Feb}$ 1;32:367-372.

99. Edel E, Houston S, Kennedy V, LaRocco M. Impact of a 5-minute scrub on the microbial flora found on artificial, polished, or natural fingernails of operating room personnel. Nurs Res. 1998 Jan;47:54-59.

100. Wynd CA, Samstag DE, Lapp AM. Bacterial carriage on the fingernails of OR nurses. AORN J. 1994 Nov;60:796-799-805.

101. Boyce JM, Pittet D, Healthcare Infection Control Practices Advisory 
Committee, HICPAC/SHEA/APIC/IDSA Hand Hygiene Task Force. Guideline for Hand Hygiene in Health-Care Settings. Recommendations of the Healthcare Infection Control Practices Advisory Committee and the HIPAC/SHEA/APIC/IDSA Hand Hygiene Task Force. Am J Infect Control. 2002;S1-S46.

102. Rotter ML. European norms in hand hygiene. J Hosp Infect. 2004;56:6-9.

103. Association of Perioperative Registered Nurses Recommended Practices Committee. Recommended practices for surgical hand antisepsis/hand scrubs. AORN J. 2004;416-431.

104. Spruce L. Back to basics: hand hygiene and surgical hand antisepsis. AORN J. 2013 Nov;98:449-460.

105. Baumgardner CA, Maragos CS, Walz J, Larson E. Effects of nail polish on microbial growth of fingernails. Dispelling sacred cows. AORN J. 1993 Jul;58:84-88.

106. Russell AD, Day MJ. Antibacterial activity of chlorhexidine. J Hosp Infect. 1993 Dec;25:229-238.

107. Fagernes M, Lingaas E, Bjark P. Impact of a single plain finger ring on the bacterial load on the hands of healthcare workers. Infec Control Hosp Epidemiol. 2007 Oct;28:1191-1195.

108. Waterman TR, Smeak DD, Kowalski J, Hade EM. Comparison of bacterial counts in glove juice of surgeons wearing smooth band rings versus those without rings. Am J Infect Control. 2006 Sep;34:421-425.

109. Cogen AL, Nizet V, Gallo RL. Skin microbiota: a source of disease or defence? Br J Dermatol. 2008 Mar;158:442-455.

110. Rehork B, Rüden H. Investigations into the efficacy of different procedures for surgical hand disinfection between consecutive operations. J Hosp Infect. 1991 Oct;19:115-127.

111. Hingst V, Juditzki I, Heeg P, Sonntag HG. Evaluation of the efficacy of surgical hand disinfection following a reduced application time of 3 instead of $5 \mathrm{~min}$. J Hosp Infect. 1992 Feb;20:79-86.

112. Pereira LJ, Lee GM, Wade KJ. The effect of surgical handwashing routines on the microbial counts of operating room nurses. Am J Infect Control. 1990 Dec;18:354-364.

113. O'Farrell DA, Kenny G, O'sullivan M, Nicholson P, Stephens M, Hone R. Evaluation of the optimal hand-scrub duration prior to total hip 
arthroplasty. J Hosp Infect. 1994 Feb;26:93-98.

114. O'shaughnessy M, O'Malley VP, Corbett G, Given HF. Optimum duration of surgical scrub-time. Br J Surg. 1991 Jun;78:685-686.

115. Suchomel M, Rotter M. Ethanol in pre-surgical hand rubs: concentration and duration of application for achieving European Norm EN 12791. J Hosp Infect. 2011 Mar;77:263-266.

116. Suchomel M, Kundi M, Pittet D, Weinlich M, Rotter ML. Testing of the World Health Organization recommended formulations in their application as hygienic hand rubs and proposals for increased efficacy. Am J Infect Control. 2012 May;40:328-331.

117. Weber WP, Reck S, Neff U, et al. Surgical hand antisepsis with alcohol-based hand rub: comparison of effectiveness after 1.5 and 3 minutes of application. Infec Control Hosp Epidemiol. 2009 May;30:420-426.

118. Kramer A, Hübner N, Below H, Heidecke C-D, Assadian O. Improving adherence to surgical hand preparation. J Hosp Infect. 2008;70:35-43.

119. Leyden JJ, McGinley KJ, Kates SG, Myung KB. Subungual bacteria of the hand: contribution to the glove juice test; efficacy of antimicrobial detergents. Infec Control Hosp Epidemiol. 1989 Oct;10:451-454.

120. Berman M. One hospital's clinical evaluation of brushless scrubbing. AORN J. 2004 Feb;79:349-54-357-8.

121. US Food and Drug Administration. Tentative final monograph for healthcare antiseptic drug products; proposed rule. Federal Register. 1994;3144131452.

122. Tanner J, Khan D, Walsh S, Chernova J, Lamont S, Laurent T. Brushes and picks used on nails during the surgical scrub to reduce bacteria: a randomised trial. J Hosp Infect. 2009 Mar;71:234-238.

123. Dineen P, Hildick-Smith G. Antiseptic care of the hands. Skin bacteria and their role in infection. New York, McGraw-Hill; 1965:291-309.

124. Rotter ML, Simpson RA, Koller W. Surgical hand disinfection with alcohols at various concentrations: parallel experiments using the new proposed European standards method. Infec Control Hosp Epidemiol. 1998 Oct;19:778-781.

125. Mitchell KG, Rawluk DJ. Skin reactions related to surgical scrub-up: results of a Scottish survey. Br J Surg. 1984 Mar;71:223-224. 
126. Loeb MB, Wilcox L, Smaill F, Walter S, Duff Z. A randomized trial of surgical scrubbing with a brush compared to antiseptic soap alone. Am J Infect Control. 1997 Feb;25:11-15.

127. Gupta C, Czubatyj AM, Briski LE, Malani AK. Comparison of two alcoholbased surgical scrub solutions with an iodine-based scrub brush for presurgical antiseptic effectiveness in a community hospital. J Hosp Infect. 2007 Jan;65:65-71.

128. Hajipour L, Longstaff L, Cleeve V, Brewster N, Bint D, Henman P. Hand washing rituals in trauma theatre: clean or dirty? Ann R Coll Surg Engl. 2006 Jan;88:13-15.

129. Pietsch H. Hand antiseptics: rubs versus scrubs, alcoholic solutions versus alcoholic gels. J Hosp Infect. 2001 Aug;48 Suppl A:S33-S36.

130. Carro C, Camilleri L, Traore O, et al. An in-use microbiological comparison of two surgical hand disinfection techniques in cardiothoracic surgery: hand rubbing versus hand scrubbing. J Hosp Infect. 2007 Sep;67:62-66.

131. Wheelock SM, Lookinland S. Effect of surgical hand scrub time on subsequent bacterial growth. AORN J. 1997 Jun;65:1087-1098.

132. Pereira LJ, Lee GM, Wade KJ. An evaluation of five protocols for surgical handwashing in relation to skin condition and microbial counts. J Hosp Infect. 1997 Apr 30;36:49-65.

133. Parienti JJ, Thibon P, Heller R, et al. Hand-rubbing with an aqueous alcoholic solution vs traditional surgical hand-scrubbing and 30-day surgical site infection rates: a randomized equivalence study. J Am Med Assoc. 2002 Aug $14 ; 288: 722-727$.

134. Weight CJ, Lee MC, Palmer JS. Avagard hand antisepsis vs. traditional scrub in 3600 pediatric urologic procedures. Urology. 2010 Jul;76:15-17.

135. Traub-Dargatz JL, Weese JS, Rousseau JD, Dunowska M, Morley PS, Dargatz DA. Pilot study to evaluate 3 hygiene protocols on the reduction of bacterial load on the hands of veterinary staff performing routine equine physical examinations. Can Vet J. 2006 Jul;47:671-676.

136. Berman RE, Knight RA. Evaluation of hand antisepsis. Arch Environ Health. 1969 May;18:781-783.

137. Nthumba PM, Stepita-Poenaru E, Poenaru D, et al. Cluster-randomized, crossover trial of the efficacy of plain soap and water versus alcohol-based rub for surgical hand preparation in a rural hospital in Kenya. Br J Surg. 2010 Nov;97:1621-1628. 
138. Zaragoza M, Sallés M, Gomez J, Bayas JM, Trilla A. Handwashing with soap or alcoholic solutions? A randomized clinical trial of its effectiveness. Am J Infect Control. 1999 Jun;27:258-261.

139. Galle PC, Homesley HD, Rhyne AL. Reassessment of the surgical scrub. Surg Gynecol Obstet. 1978 Aug;147:215-218.

140. Verwilghen DR, Mainil J, Mastrocicco E, et al. Surgical hand antisepsis in veterinary practice: evaluation of soap scrubs and alcohol based rub techniques. Vet J. 2011 Dec;190:372-377.

141. Kampf G, Shaffer M, Hunte C. Insufficient neutralization in testing a chlorhexidine-containing ethanol-based hand rub can result in a false positive efficacy assessment. BMC Infect Dis. 2005;5:48.

142. Furukawa K, Ogawa R, Norose Y, Tajiri T. A new surgical handwashing and hand antisepsis from scrubbing to rubbing. J Nippon Med Sch. 2004;71:190197.

143. Wan PY, Blackford JT, Bemis DA, Rohrbach BW, Knoll DE, Provenza MK. Evaluation of surgical scrub methods for large animal surgeons. Vet Surg. 1997 Sep;26:382-385.

144. Chen C-F, Han C-L, Kan C-P, Chen S-G, Hung PW. Effect of surgical site infections with waterless and traditional hand scrubbing protocols on bacterial growth. Am J Infect Control. 2012 May;40:e15-e17.

145. Suchomel M, Gnant G, Weinlich M, Rotter M. Surgical hand disinfection using alcohol: the effects of alcohol type, mode and duration of application. J Hosp Infect. 2009 Mar;71:228-233.

146. Olson LKM, Morse DJ, Duley C, Savell BK. Prospective, randomized in vivo comparison of a dual-active waterless antiseptic versus two alcohol-only waterless antiseptics for surgical hand antisepsis. Am J Infect Control. 2012 Mar;40:155-159.

147. Boyce JM, Kelliher S, Vallande N. Skin irritation and dryness associated with two hand-hygiene regimens: soap-and-water hand washing versus hand antisepsis with an alcoholic hand gel. Infec Control Hosp Epidemiol. 2000 Jul;21:442-448.

148. Tavolacci MP, Pitrou I, Merle V, Haghighat S, Thillard D, Czernichow P. Surgical hand rubbing compared with surgical hand scrubbing: comparison of efficacy and costs. J Hosp Infect. 2006 May;63:55-59.

149. Jehle K, Jarrett N, Matthews S. Clean and green: saving water in the operating theatre. Ann R Coll Surg Engl. 2008 Jan;90:22-24. 
150. Kramer A, Kampf G. Hand rub-associated fire incidents during 25,038 hospital-years in Germany. Infec Control Hosp Epidemiol. 2007 Jun;28:745746.

151. Bryant KA, Pearce J, Stover B. Flash fire associated with the use of alcoholbased antiseptic agent. Am J Infect Control. 2002 Jun;30:256-257.

152. Kampf G, Ostermeyer C, Kohlmann T. Bacterial population kinetics on hands during 2 consecutive surgical hand disinfection procedures. Am J Infect Control. 2008 Jun 1;36:369-374.

153. Tschudin Sutter S, Frei R, Dangel M, Widmer AF. Effect of teaching recommended World Health Organization technique on the use of alcoholbased hand rub by medical students. Infec Control Hosp Epidemiol. 2010 Nov;31:1194-1195.

154. Widmer AF, Conzelmann M, Tomic M, Frei R, Stranden AM. Introducing alcohol-based hand rub for hand hygiene: the critical need for training. Infec Control Hosp Epidemiol. 2007 Jan;28:50-54.

155. Widmer AF. Replace hand washing with use of a waterless alcohol hand rub? Clin Infect Dis. 2000 Jul;31:136-143.

156. Babb JR, Davies JG, Ayliffe G. A test procedure for evaluating surgical hand disinfection. J Hosp Infect. Elsevier; 1991;18:41-49.

157. Suchomel M, Rotter M, Weinlich M, Kundi M. Glycerol significantly decreases the three hour efficacy of alcohol-based surgical hand rubs. J Hosp Infect. 2013 Apr;83:284-287.

158. Labadie JC, Kampf G, Lejeune B, et al. Recommendations for surgical hand disinfection-requirements, implementation and need for research. A proposal by representatives of the SFHH, DGHM and DGKH for a European discussion. J Hosp Infect. Elsevier; 2002;51:312-315.

159. Bessonneau V, Thomas O. Assessment of Exposure to Alcohol Vapor from Alcohol-Based Hand Rubs. Int J Enviro Res Public Health. 2012 Mar 13;9:868-879.

160. Singh A, Walker M, Rousseau J, Monteith GJ, Weese JS. Methicillin-resistant staphylococcal contamination of clothing worn by personnel in a veterinary teaching hospital. Vet Surg. 2013 Aug;42:643-648.

161. Koransky JR, Allen SD, Dowell VR. Use of ethanol for selective isolation of sporeforming microorganisms. Appl Environ Microbiol. 1978 Apr;35:762765. 
162. Corder K, Knowles TG, Holt PE. Factors affecting bacterial counts during preparation of the hands for aseptic surgery. Vet Rec. 2007 Jun 30;160:897901.

163. Verwilghen D, Singh A. Fighting surgical site infections in small animals: are we getting anywhere? Vet Clin North Am Sm Anim Pract. 2015 Mar;45:24376-v.

164. US Food and Drug Administration. Safety and Effectiveness of Health Care Antiseptics; Topical Antimicrobial Drug Products for Over-the-Counter Human Use. 2015;1-41. 